\title{
COMO SALVAR A AMAZÔNIA: POR QUE A FLORESTA DE PÉ VALE MAIS DO QUE DERRUBADA ${ }^{1}$ \\ HOW TO SAVE THE AMAZON: WHY THE FOREST HAS MORE VALUE STANDING THAN CUT DOWN
}

\author{
Luís Roberto Barroso ${ }^{2}$ \\ Patrícia Perrone Campos Mello 3
}

\section{Resumo}

O presente artigo expõe a importância da Amazônia no ecossistema global, o recuo e o avanço do desmatamento da floresta situada em território brasileiro, assim como a dinâmica da escalada dos crimes ambientais, com destaque para a extração ilegal de madeira, a grilagem de terras e o garimpo não autorizado, inclusive em reservas indígenas. $O$ texto aponta as políticas públicas governamentais que tiveram sucesso em conter a destruição da floresta e o retrocesso que sofreram nos últimos tempos. Na parte final, são descritos os modelos de exploração da floresta adotados até aqui, com limitados resultados econômicos e sociais, e apresenta-se o modelo alternativo que vem sendo proposto, combinando a Quarta Revolução Industrial com a bioeconomia da floresta. Apresentam-se, ainda, as contribuições que os atores internacionais podem oferecer à preservação da floresta, através de financiamento (REDD+), bem como da formulação de exigências dos mercados consumidores e financiadores das atividades desenvolvidas na Amazônia Legal.

Palavras-chave: Amazônia, desmatamento, crime ambiental, modelos de exploração econômica, quarta revolução industrial, financiamento (REDD+).

\footnotetext{
${ }^{1}$ Os autores são gratos ao Pesquisador Beto Veríssimo (Imazon), ao ISA-Instituto Socioambiental, ao Senador Randolphe Gomes, ao General Fernando Azevedo e Silva, aos Professores Marcelo Varella (UniCeub) e José Heder Benatti (UFPA), bem como aos servidores do CENSIPAN, pela valiosa contribuição para o presente estudo. E aos acadêmicos Clara de Carvalho (Harvard), Clara Lacerda Accioly (UnB) e Lucas Soriano Ferreira (UnB), pelo auxílio na pesquisa.

2 Mestre pela Universidade de Yale, Doutor e Livre-Docente pela Universidade do Estado do Rio de Janeiro UERJ. Visiting Scholar na Faculdade de Direito de Harvard e Senior Fellowna Harvard Kennedy School. Professor titular da UERJ. Ministro do Supremo Tribunal Federal. Universidade do Estado do Rio de Janeiro - UERJ - Brasil. Lattes: http://lattes.cnpq.br/2430424576721113 ORCID: 0000-0003-3407-2304 E-mail: gabmlrb@stf.jus.br

${ }^{3}$ Mestre e Doutora em Direito pela Universidade do Estado do Rio de Janeiro - UERJ. Visiting Researcherno Max Planck Institute for Comparative Public Law and International Law. Professora do Centro Universitário de Brasília - UniCeub. Assessora de Ministro do Supremo Tribunal Federal. Procuradora do Estado do Rio de Janeiro. Centro Universitário de Brasília - UniCeub - Brasil. Lattes: http://lattes.cnpq.br/5868299371482978 ORCID: 0000-0003-2929-5642 E-mail: pcamposmello@uol.com.br
} 


\begin{abstract}
This paper discusses the importance of the Amazon to the global ecosystem, the reduction and the advance of deforestation of the forest in Brazilian territory, as well as the escalation of environmental crimes, with emphasis on illegal logging, land grabbing and unauthorized mining, including in indigenous lands. The text points to public policies that have been successful in containing the destruction of the forest and the setback they have suffered in recent times. In the final part, the article describes the forest exploitation models adopted so far, with their limited economic social results, and presents an alternative model, which combines the Fourth Industrial Revolution and forest bioeconomy. Finally, the paper also presents contributions that international agents can offer to the preservation of the forest, through financing (REDD+ mechanisms), as well as conditionalities formulated by consumer and financing markets.
\end{abstract}

Keywords: Amazon, deforestation, environmental crime, economic exploitation models, fourth industrial revolution, financing (REDD+).

\title{
Introdução
}

AMAZÔNIA: SEGURANÇA HUMANA, DESENVOLVIMENTO SUSTENTÁVEL

E PREVENÇÃO DE CRIMES

\section{Apresentação do tema}

O artigo que se segue foi escrito para servir de base à conferência a ser proferida pelo primeiro autor no XIV Congresso das Nações Unidas sobre Prevenção do Crime e Justiça Criminal, originariamente previsto para abril de 2020, em Kyoto, no Japão. A pandemia do COVID-19, no entanto, impôs o adiamento do evento. A preocupação central do trabalho é identificar as causas do desmatamento da Amazônia brasileira, bem como superar a indiferença e o desconhecimento que ainda prevalecem em círculos importantes acerca da gravidade do problema. Ao longo do texto, após breve apresentação geopolítica da região amazônica, procura-se demonstrar o risco real de perecimento da floresta, os mecanismos perversos que têm levado à sua destruição e quais os caminhos para sua preservação.

A Amazônia ou Bacia Amazônica ocupa uma área em torno de 7 milhões de $\mathrm{Km}^{2}$, correspondentes a cerca de $40 \%$ da América do Sul (BARBOSA, 2015, p. 1) e a 67\% das florestas tropicais do mundo (IMAZON, 2013). Aproximadamente $5.500 .000 \mathrm{Km}^{2}$ são de densa floresta tropical. 
A região compreende o território de 9 países $^{4}$, mas 60\% de sua extensão situam-se no Brasil. Cerca de

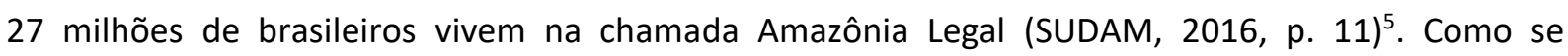
aprofundará ao longo do presente estudo, a Amazônia é a maior reserva de biodiversidade do mundo, tendo influência decisiva na estabilidade climática do Brasil e do planeta, entre outras razões, pela retenção de carbono, por seu papel no regime de chuvas e como curso de água doce que deságua no Oceano Atlântico. A região também é o habitat de uma variedade de povos e culturas, inclusive dezenas de tribos indígenas, algumas sem contato com a civilização ${ }^{6}$. Desde os anos 70 do século passado, formou-se uma crítica dualidade acerca do tratamento a ser dado à floresta: de um lado os desenvolvimentistas e, de outro, os ambientalistas. O presente trabalho explorará essa tensão, em busca do equilíbrio possível entre as duas vertentes. Já se adianta, desde logo, no entanto, que o desmatamento é visto pelos autores como um fato grave, indesejável e que compromete negativamente a região, o país e o planeta.

A análise levada a efeito nesse texto tem como fio condutor três conceitos essenciais na matéria: segurança humana, desenvolvimento sustentável e prevenção de crimes ambientais. A expressão segurança humana constitui ampliação e aprofundamento de ideias como dignidade humana, direitos fundamentais e mínimo existencial (basic needs), sedimentadas, sobretudo, depois da 2a Guerra Mundial ${ }^{7}$. Em apertada síntese, é possível dizer que ela se materializa em três liberdades essenciais e complementares: a de não ter medo, a de não passar privações materiais e a de viver com dignidade (UN, 2005). O significado de desenvolvimento sustentável foi delineado nos últimos 50 anos em diferentes encontros e documentos internacionais ${ }^{8}$. Desde a clássica formulação do Relatório Brundtland, de 1987, desenvolvimento sustentável vem sendo definido como aquele que satisfaz as necessidades do presente, sem comprometer a capacidade das futuras gerações de satisfazerem suas

\footnotetext{
${ }^{4}$ Bolívia, Brasil, Colômbia, Equador, Guiana Francesa, Guiana, Peru, Suriname e Venezuela.

${ }^{5}$ O governo brasileiro criou o conceito de Amazônia Legal, que inclui, além dos Estados da região Norte (Acre, Amapá, Amazonas, Pará, Rondônia e Roraima), também o Mato Grosso, Tocantins (região Centro-Oeste) e o Oeste do Maranhão (região Nordeste). V. Lei n. 5.173, de 27 out. 1966 e Lei Complementar n. 124, de 3 jan. 2007. Interessante observar que a Amazônia Legal abrange não apenas o bioma de floresta tropical, mas também o cerrado e o pantanal.

${ }^{6}$ São 170 povos indígenas e estima-se que 46 deles são isolados ou de pouco contato. V. Abramovay, 2019, p. 55.

7 Segurança humana é um conceito multidimensional, centrado no indivíduo, abrangendo sete domínios: (i) pessoal (integridade física), (ii) econômico (renda básica), (iii) alimentar (nutrição mínima), (iv) saúde (proteção contra doenças), (v) comunitário (proteção da diferença e dos valores identitários), (vi) liberdades políticas (direitos, liberdades e participação) e (vii) ambiental (proteção contra a degradação ambiental) (UN, 1994, pp. 3, 24-33).

${ }^{8}$ Alguns marcos dessa trajetória foram a reunião do Clube de Roma, de 1972, a ECO 92, no Rio de Janeiro e a aprovação, em 2015, dos Objetivos de Desenvolvimento Sustentável.
} 
próprias necessidades (UN, 1987), assegurando o equilíbrio adequado entre crescimento econômico, proteção ambiental e progresso social. São três, portanto, os seus pilares: social, ecológico e econômico ${ }^{9-10}$. Por fim, o grande papel do direito penal é o de funcionar como prevenção geral de crimes (deterrence), dissuadindo os indivíduos de cometê-los pela probabilidade real de serem punidos. A falta de fiscalização e de repressão adequada dos crimes ambientais dá incentivos comportamentais errados, que contribuem para a degradação da Amazônia.

\section{Parte I}

\section{O QUADRO ATUAL:}

\section{0 risco de perecimento da floresta}

\section{A MUDANÇA CLIMÁTICA}

Desde a primeira Revolução Industrial, em meados do século XVIII, a temperatura da Terra vem subindo ${ }^{11}$, fenômeno identificado como aquecimento global ou, de forma mais abrangente, mudança climática ${ }^{12}$. A maior parte dos cientistas afirma que o fenômeno da mutação climática se deve, sobretudo, à ação humana (NASA, s/d.a), embora existam, ainda, céticos e negacionistas ${ }^{13}$. 0 Painel Intergovernamental sobre Mudança Climática, criado em 1988, no âmbito das Nações Unidas, para consolidar o conhecimento científico na matéria, considera que a probabilidade de o homem ser responsável pelo aquecimento global é superior a 90\% (IPCC, 2008). É fora de dúvida que o planeta está em fase de aquecimento e muitas das consequências já podem ser sentidas em diferentes partes do mundo, como o derretimento das calotas polares, a elevação do nível do mar, a extinção de espécies e o número crescente de situações climáticas extremas (como furacões, enchentes, secas e ondas de calor). A principal causa do aquecimento global é a emissão de gases de efeito estufa - que aumentam a retenção de calor na atmosfera -, decorrente, entre outros fatores, da queima de combustíveis fósseis (NASA, s/d.b) e de mudanças no uso e cobertura do solo, associados à agricultura, pecuária, manuseio de lixo e desmatamento (JIA; SHEVILAKOVA; ARTAXO, 2019, p. 133). E aí entra a

\footnotetext{
${ }^{9}$ Entre os Objetivos do Desenvolvimento Sustentável, aprovados pela ONU, em 2015, o Objetivo 15 assim prevê: "Proteger, recuperar e promover o uso sustentável dos ecossistemas terrestres, gerir de forma sustentável as florestas, combater a desertificação, deter e reverter a degradação da terra e deter a perda de biodiversidade". ${ }^{10}$ Instituições como a UNESCO sugerem um quarto pilar, que seria a Educação, inclusive ambiental. UNESCO, Sustainable development. Disponível em: <https://en.unesco.org/themes/education-sustainabledevelopment/what-is-esd/sd>. Acesso em 24 jan. 2020. Para uma síntese da evolução do conceito de desenvolvimento sustentável no Direito Internacional, v. Varella, 2009, pp. 6-25.

${ }^{11} \mathrm{~A}$ temperatura global já aqueceu ${ }^{1}$ ㅇ C desde a Revolução Industrial. E, segundo estimativas, terá se elevado em $3 \circ \mathrm{C}$ até o final desse século, ultrapassando o teto de $2^{\circ} \mathrm{C}$ fixado pelo Acordo de Paris e o anunciado esforço para que não superasse $1,5=\mathrm{C}$.

${ }^{12} \mathrm{~V}$. Romm, s/d.

${ }^{13} \mathrm{~V}$. Open Source Systems, s/d; Demelle, s/d.
} 
questão da Amazônia, cuja área de floresta foi reduzida em escala grandiosa nas últimas décadas. Florestas tropicais desempenham papel destacado na mitigação climática, por sua capacidade de retenção de carbono, como já observado.

Três documentos internacionais patrocinados pela ONU vêm procurando enfrentar diretamente o problema da mudança climática: (i) a Convenção Quadro sobre Mudança Climática, de 1992; (ii) o Protocolo de Kyoto, concluído em 1997, mas que só entrou em vigor em 2005; e (iii) o Acordo de Paris, vigente desde o final de 2016. Está prevista para 2023 uma avaliação geral dos resultados obtidos. Já se antecipa que as metas de redução das emissões não terão sido alcançadas e que, ademais, têm se revelado insuficientes. O quadro geral é agravado pela decisão dos Estados Unidos de se retirarem do Acordo de Paris. Não por acaso, no Fórum Econômico Mundial de 2020, em Davos, na Suíça, as maiores preocupações e discussões de lideranças políticas, econômicas e intelectuais gravitaram em torno do aquecimento global, da mudança climática e da perda de biodiversidade (WORLAND, 2020). Sintomaticamente, como noticiado pela imprensa, a estrela do evento foi a jovem ativista sueca Greta Thunberg, e não os chefes de Estado que lá compareceram. Mudança climática e sustentabilidade são temas que finalmente vão ingressando no mainstream do pensamento mundial, fato que já começa a impactar decisões econômicas, financeiras, comerciais e regulatórias. $O$ desinvestimento em combustíveis fósseis vem se tornando uma exigência global (CARRINGTON, 2020; FOSSIL FREE DIVESTMENT, s.d). E crescem os reclamos por um "novo capitalismo", mais humano, ecológico e igualitário ${ }^{14}$.

\section{A IMPORTÂNCIA DA FLORESTA AMAZÔNICA}

Estima-se que a Floresta Amazônica exista há 55 milhões de anos (MORLEY, 2000) havendo notícia de que seja habitada por seres humanos há pelo menos 11.200 anos (ROOSEVELT; LIMA DA COSTA; LOPES MACHADO; MICHAB et al, 1996). Trata-se da maior floresta tropical do mundo, que desempenha um papel crítico no equilíbrio ecológico do planeta, por múltiplas razões. Em primeiro lugar, por sua extraordinária biodiversidade, constituindo a maior concentração de plantas, animais,

\footnotetext{
${ }^{14} \mathrm{O}$ ex-vice Presidente dos Estados Unidos, Al Gore, afirmou: "A versão de capitalismo que nós temos hoje no mundo precisa ser reformada" ("The version of capitalism we have today in our world must be reformed"), segundo reportou Worland (2020), onde acrescentou: "É pertinente dizer que o tema oficial do encontro de Davos deste ano é "capitalismo melhor".
} 
fungos, bactérias e algas da Terra ${ }^{15}$. Desnecessário enfatizar que a derrubada da floresta produz a extinção de espécies, com imprevisíveis consequências sistêmicas para o meio ambiente ${ }^{16}$.

Uma segunda razão para a importância da Floresta Amazônica é o seu papel no ciclo da água e no regime de chuvas, com implicações por todo o continente sul-americano, por meio da evotranspiração ${ }^{17}$ e da atração e transferência de umidade dos oceanos para o interior do continente. A evotranspiração ocorre quando árvores e plantas absorvem água do solo para realizarem a fotossíntese ${ }^{18}$ e para se resfriarem. Essa água é liberada pelos poros das folhas, sob a forma de vapor, transformando-se em nuvens (SMITH, 2019). O fenômeno se processa com grande absorção de calor da superfície, resfriando a atmosfera e, ao mesmo tempo, devolvendo-lhe umidade. A umidade produz nuvens de chuva que reabastecem o solo da própria floresta. Além disso, a Floresta Amazônica atrai e transfere grandes volumes de umidade do oceano para outras regiões por meio de "rios voadores": fluxos atmosféricos de vapor que conectam áreas doadoras de umidade com áreas receptoras de umidade, contribuindo para irrigar outras bacias hidrográficas ${ }^{19}$.

Em terceiro lugar, a floresta desempenha função de grande importância na mitigação do aquecimento global, absorvendo e armazenando dióxido de carbono, por meio da fotossíntese. Como intuitivo, com o desmatamento, ela não apenas deixa de absorver carbono como o libera de volta na atmosfera $^{20}$. Especialistas afirmam, todavia, não ser correta, a crença de que a Amazônia seja o "pulmão do mundo". A floresta, na verdade, absorve todo o oxigênio que produz. A expressão, em

\footnotetext{
${ }^{15}$ Estima-se que existam na região cerca de 60.000 espécies de plantas (das quais 30.000 de plantas superiores, sendo mais de 2.500 espécies de árvores), 2,5 milhões de espécies de artrópodes (insetos, aranhas, centopéias, etc.), 2.000 espécies de peixes e 300 de mamíferos (CÂMARA DOS DEPUTADOS, 2019).

${ }^{16} \mathrm{Em}$ recente entrevista à BBC News Mundo, o biólogo Sean B. Carroll, rememorando pesquisas pioneiras de Robert Paine, Jim Estes e Mary Power, citou exemplos diversos de conexões ocultas completamente inesperadas entre as criaturas e a natureza, demonstrando a importância das chamadas espécies-chave para a preservação da biodiversidade. É preciso anos de pesquisas de campo para identificá-las. Alguns exemplos, em variados ecossistemas, são estrelas do mar, lontras-marinhas, certos tipos de peixes fluviais, baleias ou lobos. Alguns são predadores, outros são alimentos, mas todos são indispensáveis para a preservação de outras espécies. V. Ventura, 2020.

${ }^{17}$ Evotranspiração é a combinação de dois processos do ciclo da água: evaporação da água do solo e da vegetação e transpiração das plantas, liberando vapor na atmosfera.

${ }^{18}$ Explicada de uma maneira simples, fotossíntese é a transformação de energia solar em energia química. É um processo que requer luz solar, água e dióxido de carbono. Plantas (e alguns outros organismos) absorvem e combinam esses três elementos, produzindo açúcar (glucose) e oxigênio. V. Science and Technology Concepts Middle School, 2017.

${ }^{19}$ V. Nobre, 2014, p. 18.

${ }^{20}$ Aponta-se, ainda, que grandes áreas terrestres cobertas por florestas funcionam como obstáculo à formação de furacões e de outros eventos climáticos extremos. V. Nobre, 2014, p. 19-20.
} 
rigor, poderia ser aplicada às algas nos oceanos, que desempenham papel muito mais importante na produção de oxigênio (SOLIGEN, 2010, p. 270).

\section{ReCuo e AVANço do desmatAMENTO}

Até o início dos anos 60 do século XX, a Floresta Amazônica brasileira permaneceu praticamente intacta. A situação começou a se alterar na virada dos anos 60 para os anos 70 , com a ampliação do desmatamento sendo devida, sobretudo, à ação do próprio Poder Público, pela construção de estradas, infraestrutura, incentivos à colonização e subsídios para a agricultura (CELENTANO; SILLS; SALLES; VERÍSSIMO, 2012, p. 850). Era ainda um período de mínima consciência ambiental. Entre 1970 e 1990, 7,4\% da floresta foram desmatados, com perda de $303.712 \mathrm{Km}^{2}$, passando de uma área pré-1970 de $4.100 .000 \mathrm{~km}^{2}$ para $3.796 .288 \mathrm{Km}^{2}$ (BUTLER, 2018). O desflorestamento seguiu de maneira progressiva até chegar ao seu ápice, em 2004, quando foi desmatada uma área equivalente a $27.772 \mathrm{~km}^{2}$ (INPE, s.d.). Nesse ano de 2004, foi deflagrado um ambicioso programa denominado Plano de Prevenção e Controle do Desmatamento na Amazônia (PPCDAm), com iniciativas nos campos institucional, legal e político (CAPOBIANCO, 2017). O plano foi executado em diferentes fases, com medidas que incluíram (i) monitoramento do desmatamento por imagens de satélite em tempo real, (ii) fiscalização efetiva para coibir extração ilegal de madeira e outras infrações, (iii) combate à grilagem de terras, (iv) criação de unidades de conservação (reservas florestais), (v) demarcação de terras indígenas e (vi) corte de créditos subsidiados para produtores que não tinham titularidade da terra ou não respeitavam as normas ambientais ${ }^{21}$.

O PPCDAm produziu resultados notáveis: entre 2004 e 2012, o desmatamento caiu mais de $80 \%$, passando para menos de $4.600 \mathrm{~km}^{2}$ (INPE, s/d). O Brasil foi o país que mais contribuiu, no período, para a mitigação da mudança climática (KALUNGA, 2020). Um dado digno de registro é que o desmatamento é significativamente menor nas áreas indígenas demarcadas (HUMAN RIGHTS WATCH, 2019). Outro ponto de destaque é que a atuação efetiva do Poder Público, com vontade política, coordenação e visibilidade - inclusive na mídia - aumentou em intensidade relevante a percepção de risco no descumprimento da legislação ambiental (CAPOBIANCO, 2017, p. 140).

O sucesso das medidas inspirou a crença de que se poderia dar um passo à frente, chegando ao estágio ideal do desmatamento líquido zero (VERÍSSIMO, 2015). Lamentavelmente, contudo, a

\footnotetext{
${ }^{21}$ V. MMA, s/d.a; HRW, 2019; e Capobianco, 2000, p. 33.
} 
partir de 2013, arrefeceu a determinação em cumprir o PPCDAm e o desmatamento voltou a crescer, chegando a $7.536 \mathrm{~km}^{2}$ em 2018 (INPE, s/d). No ano de 2019, atingiu-se quase $10.000 \mathrm{~km}^{2}$. No total, o desflorestamento acumulado nos últimos 50 anos é de cerca de $800.000 \mathrm{~km}^{2}$, aproximando-se de $20 \%$ da área original da Amazônia brasileira (VERÍSSIMO, 2015) ${ }^{22}$. O desmatamento costuma seguir uma dinâmica constante: extração ilegal de madeira, queimada, ocupação por fazendeiros e produtores (gado e soja) e tentativa de legalização da área pública grilada. Na parte sudeste da floresta, estudos sugerem que a estação seca está se tornando mais quente e longa, em resposta à atuação antropogênica (BARKHORDARIAN et al, 2019). Cientistas consideram que se a derrubada da floresta chegar a 40\% haverá um ponto de não retorno (tipping point) (NOBRE; SAMPAIO; BORMA; CASTILLARUBIO; SILVA; CARDOSO, 2016). E estudos mais recentes apontam que, uma vez atingidos 20 a $25 \%$ de desmatamento, a Amazônia passará por mudanças irreversíveis, com tendência à savanização (LOVEJOY; NOBRE, 2018). As consequências de um mundo sem a Amazônia são "catastróficas" para o planeta e para o Brasil. Além do incremento do aquecimento global, haverá redução drástica das chuvas que, no caso brasileiro, são imprescindíveis para o agronegócio e para a geração de energia (SALLES; ESTEVES, 2019). A escassez de água comprometerá, ainda, a indústria, o abastecimento das populações e a vida nas cidades.

\section{Parte II}

\section{O CAMINHO DA DEGRADAÇÃO:}

\section{A dinâmica perversa da destruição da floresta}

\section{OS CRIMES AMBIENTAIS}

Crimes ambientais são reconhecidos, atualmente, como uma das mais lucrativas formas de atividade criminosa transnacional, com a agravante de ser baixo o risco de punição (UN, 2018) ${ }^{23}$. Inexiste uma definição doutrinaria única para essa espécie de delito. Para os fins desse estudo, considera-se crime ambiental a conduta ou atividade ilícita que prejudica o ecossistema, causando dano ao meio ambiente (solo, ar e água), à biodiversidade (fauna e flora) ou contribuindo para o esgotamento de recursos naturais (orgânicos ou inorgânicos, como peixes, madeira e minerais) ${ }^{24}$. Nos

\footnotetext{
${ }^{22}$ Vale, contudo, registrar que os dados oficiais sobre desmatamento identificam apenas as áreas onde a floresta foi completamente retirada. Não contabilizam as áreas degradadas que, se consideradas, implicariam supressão vegetal bem superior.

${ }^{23}$ Trata-se da quarta principal forma de criminalidade no mundo, atrás de drogas, falsificações e tráfico de pessoas, girando entre 91 e 259 bilhões de dólares anualmente.

${ }^{24}$ Elementos dessa definição se encontram em INTERPOL; UNEP, 2016.
} 
últimos anos, desenvolveu-se, inclusive, um novo ramo da criminologia, identificado como criminologia verde ${ }^{25}$. Quando praticados em larga escala, os crimes ambientais exigem uma organização criminosa estruturada e uma cadeia de agentes econômicos que abrange produtores, intermediários e compradores. Muitas vezes, crimes ambientais são praticados em conexão com outros crimes, como lavagem de dinheiro, corrupção de agentes públicos, contrabando e trabalho escravo. É importante observar que nem todas as atividades que causam dano ambiental são tratadas pela legislação como crime - embora sejam reguladas e possam dar lugar a infrações administrativas. São exemplos de tais atividades: o uso generalizado de combustíveis fósseis, a geração de energia por usinas termoelétricas e aterros sanitários, para mencionar três delas que causam relevante impacto ambiental.

São inúmeros os crimes ambientais em espécie, tipificados na legislação dos diferentes países, inclusive do Brasil ${ }^{26}$. A seguir, a identificação e descrição dos principais deles, com ênfase no seu impacto sobre a região amazônica:

1. Desmatamento e queimadas. O desmatamento é um crime em $\mathrm{si}^{27}$, embora possa estar associado a diversos outros crimes, como se verá a seguir. Trata-se do principal delito ambiental praticado na Amazônia, de acordo com dados de processos criminais que chegam aos tribunais ${ }^{28}$. Há muitas causas que impulsionam o desmatamento, entre elas a urbanização, a indústria da madeira e a produção de lenha e carvão (este fator é mais significativo nas florestas africanas) (UN ENVIRONMENT PROGRAMME, 2018). Todavia, o principal agente de desmatamento na Floresta Amazônica é a pecuária, com a constituição de pastos em fazendas de criação de gado. Embora em menor escala, também a agricultura contribui para o desflorestamento. Algumas culturas que já estiveram ou estão associadas a esse crime são a soja, o arroz e a cana de açúcar em algumas regiões. A despeito da legislação rígida, o desmatamento ocorre tanto em terras privadas quanto públicas, assim como em áreas indígenas e em unidades de conservação, embora nas últimas em escala bem

\footnotetext{
${ }^{25}$ V. Lynch; Stretesky, 2012; International Green Criminology Working Group, s/d.

${ }^{26}$ No Brasil, os crimes ambientais estão definidos na Lei $n 9.605$, de 12 fev. 1998, que os classifica nos seguintes gêneros: (i) crimes contra a fauna, (ii) crimes contra a flora, (iii) poluição e outros crimes, (iv) crimes contra o ordenamento urbano e (v) crimes contra a administração ambiental.

27 Lei n 9.605/98 (Lei de Crimes Ambientais), arts. 38, 39 e 40.

28 Pesquisa realizada pelos autores no banco de dados do Superior Tribunal de Justiça, com base no verbete "crime\$ adj2 ambient\$ e (AM ou RO ou RR ou PA ou MT uo AC ou TO)", referente ao período de 01.01.2010 a 01.01.2010. Na mesma linha, v. Azevedo; Vieira, 2018, p. 262.
} 
menor, como já observado ${ }^{29}$. Contribui para esse quadro a deficiência na fiscalização, na repressão e na execução de decisões judiciais.

Queimadas são, no mais das vezes, causas ou consequências do desmatamento, sendo muitas delas de natureza criminosa ${ }^{30}$, com o propósito de desfazer-se da vegetação nativa e permitir a pecuária e a agricultura ${ }^{31}$, provocando graves danos à floresta e à saúde da população (ROCHA, 2017). Em 2019, a situação tornou-se de extrema gravidade, com aumento expressivo de focos de incêndio em relação a anos anteriores ${ }^{32}$. Em meio a grande desgaste doméstico e internacional, com acusações de incentivos indevidos e de leniência em relação aos incêndios florestais, o Governo Federal deflagrou a Operação Brasil Verde, que mobilizou mais de 9 mil mulheres e homens, entre civis e militares, coordenados pelo Ministério da Defesa. Dados oficiais sustentam o êxito da operação em debelar a crise (MINISTÉRIO DA DEFESA, 2019) ${ }^{33}$.

2. Extração e comércio ilegal de madeira. Este é o segundo crime mais praticado na Amazônia $^{34}$, segundo revelam pesquisas nos tribunais ${ }^{35}$. Embora a extração ilegal de madeira não seja a principal causa de desmatamento, ela presta contribuição decisiva, por ser a porta de entrada de outros empreendimentos criminosos ou ilegais que são deletérios para a Floresta Amazônica. O mais importante deles é a apropriação privada de terras públicas para venda em lotes e subsequente criação de gado ou uso para a agricultura. A retirada das árvores mais elevadas e valiosas permite a passagem da luz solar, secando a vegetação e deixando-a mais propícia a queimadas, deliberadas ou naturais

\footnotetext{
${ }^{29}$ Nas terras de propriedade ou posse privadas, as chamadas áreas de preservação permanente (APP) devem ter sua vegetação inteiramente preservada, ao passo que nas demais terras, se situadas em áreas de floresta, impõese a observância de uma reserva legal de preservação de $80 \%$ da cobertura vegetal nativa. V. Código Florestal Lei 12.651, de 25 mai. 2012, arts. 7 e 12, l, a.

${ }^{30}$ Lei n 9.605/98 (Lei de Crimes Ambientais), art. 41: "Provocar incêndio em mata ou floresta: Pena - reclusão de dois a quatro anos, e multa".

${ }^{31}$ V. Barlow et al, 2019; Vick, 2019. São identificados três tipos de queimadas: (i) pós-desmatamento: derrubase a vegetação, deixada a secar ao sol e depois queimada para preparar a terra para pecuária e agricultura; (ii) para fins agrícolas ou de pecuária: pecuaristas queimam para destruir ervas daninhas e agricultores, inclusive indígenas e povos tradicionais, pelo uso da técnica corte e queima; e (iii) incêndio florestal: ocorre quando a queimada foge de controle e invade a floresta.

32 De acordo com o Instituto Nacional de Pesquisas Espaciais - INPE, entre agosto de 2018 e julho de 2019, houve destruição de $9.762 \mathrm{Km}^{2}$ de floresta, uma alta de 29,5\% em relação aos 12 meses precedentes. (INPE, 2019). Os focos de queimadas subiram 30\% e chegaram a 89 mil (REUTERS, 2020).

33 "Dados de quase 40 dias da Operação Verde Brasil indicam a marca de 1,7 mil focos de incêndios combatidos, 73 pessoas detidas e 237 termos de infração lavrados, que resultaram na aplicação de $\mathrm{R} \$ 55$ milhões em multas" (MINISTÉRIO DA DEFESA, 2019).

${ }^{34}$ Lei n 9.605/98 (Lei de Crimes Ambientais), arts. 45, 46 e par. único.

${ }^{35}$ Pesquisa realizada no Tribunal Regional Federal da 1a Região pelos autores, com base no verbete: “crime\$ adj2 ambient\$ e (AM ou PA ou MT)". O levantamento se limitou aos Estados do Pará, Mato Grosso e Amazonas, bem como ao período de 01.01.2010 a 01.01.2020,
} 
(WALLACE, 2019). Os madeireiros "lavam" a madeira ilegal usando documentação fraudulenta, que dá a ela a aparência de ter sido obtida em área de exploração legal (HRW, 2019). Vale dizer: por não terem seu potencial adequadamente inventariado, áreas licenciadas "produzem" volume de madeira muito superior à sua real capacidade. $\mathrm{E}$, assim, encobrindo a origem ilícita, conseguem acesso aos mercados internacionais, como União Europeia, Estados Unidos e China. Estima-se que $80 \%$ da produção de madeira no Brasil seja produto de extração ilegal ${ }^{36}$. Alguns comparam esse mercado ao de tráfico de drogas (SOLIGEN, 2010, p. 265).

A extração ilegal de madeira dá lugar a um fenômeno distinto do desmatamento, que é a degradação florestal. Trata-se do empobrecimento gradual da floresta, como consequência do corte seletivo de árvores mais nobres. Como o monitoramento por satélite somente detecta áreas que são integralmente desmatadas, a degradação nem sempre é identificada por essa via, embora implique em desequilíbrio profundo do ecossistema. Muitas dessas árvores são habitat preferencial de diferentes aves, insetos e mamíferos e sua derrubada pode provocar extinção de espécies e abalar toda uma cadeia biológica (ISA, 2019b). A extração ilegal de madeira envolve redes criminosas que têm capacidade logística de coordenar o corte, o processamento e a venda de madeira em larga escala. Além disso, tais redes têm o poder de corromper autoridades e de empregar milícias armadas (HRW, 2019, p. 28) ${ }^{37}$. Há problemas sociais e políticos associados a essa modalidade de crime: existem cidades que chegam a ter até 20 serrarias (sawmills), que empregam algumas centenas de trabalhadores e são o sustento de suas famílias. Além disso, há uma contaminação da política por essa atividade ilegal, pois muitos dos envolvidos são eleitos vereadores, prefeitos e deputados estaduais (HRW, 2019).

3. Garimpo e mineração ilegais. A mineração ilegal, sobretudo de ouro, está presente em quase todos os estados da Amazônia Legal brasileira, camuflada sob o título "garimpo" ${ }^{38}$. Na verdade, embora ainda exista, residualmente, o garimpeiro individual, com picareta e bateia, a extração de ouro, nos dias atuais, se faz com maquinário pesado, de custo financeiro elevado e alto impacto ambiental, que inclui balsas, dragas e escavadeiras hidráulicas (MPF, 2020, p. 8). A mineração contribui para o desmatamento em menor escala que outras atividades humanas, como pecuária e extração de

\footnotetext{
${ }^{36}$ INTERPOL; UNEP, 2016. Há estimativas ainda mais elevadas, v. Farias, 2019.

${ }^{37}$ A esse propósito, episódio emblemático ocorreu em Espigão do Oeste, no Estado de Rondônia, em 4 de julho de 2019, quando um caminhão tanque que carregava combustível de aviação para helicópteros da fiscalização ambiental foi atacado e incendiado a mando de madeireiros locais. V. Wallace, 2019.

${ }^{38}$ Apesar de uma certa indeterminação legislativa, é possível conceituar garimpo como a atividade de extração mineral conduzida por pessoas físicas, independentemente de prévia pesquisa, com instrumentos e técnicas rudimentares e área máxima limitada; ao passo que mineração é uma atividade industrial, precedida de pesquisa, em escala bem maior, geralmente desenvolvida por empresas especializadas.
} 
madeira. Ainda assim, estudo recente concluiu que, entre 2005 e 2015, ela foi responsável por cerca de $10 \%$ da perda de cobertura vegetal na Amazônia brasileira (SONTER et al 2017) ${ }^{39}$. Mais de $90 \%$ do desflorestamento se deu em sítios de exploração mineral ilegais, isto é, sem concessão do Governo brasileiro (IONOVA, 2019). Atualmente, existem mais de 450 áreas nessa situação (IONOVA, 2019), várias delas, inclusive, com pistas de pouso clandestinas (ISA, 2019a $)^{40}$. Inexiste controle adequado para distinguir mineração legal de ilegal. Sintomaticamente, em 2019, o ouro se tornou o produto mais exportado do Estado de Roraima, que não possui nenhuma mina operando legalmente (ASSOCIAÇÃO MINEIRA DE DEFESA DO MEIO AMBIENTE, 2019).

Além do desmatamento e das cicatrizes sobre a terra, há outros problemas graves associados à mineração ilegal. Um deles é a poluição dos rios, causada pelo uso do mercúrio na exploração do ouro, contaminando a água e os peixes consumidos pelas populações locais ${ }^{41}$. Outro problema é a invasão de áreas protegidas e, sobretudo, de terras indígenas, como, por exemplo, a dos Yanomamis (Roraima e Amazonas), dos Kayapós e Munduruku (ambas no Pará) ${ }^{42}$, onde há alguns milhares de garimpeiros atuando. O Exército tem papel decisivo na proteção dessas áreas e, quando ele se retira, ocorre o avanço ilegal (ISA, 2019a) ${ }^{43}$. O garimpo em terras indígenas acarreta assoreamento dos rios, conflitos pela terra, criminalidade, doenças e prostituição ${ }^{44}$. A Constituição brasileira admite a possibilidade de exploração de recursos minerais em terras indígenas, mas condicionada à prévia aprovação de lei regulamentadora, que nunca foi editada. No início de 2020, o Presidente da República enviou ao Congresso Nacional projeto de lei sobre a matéria ${ }^{45}$, que foi recebido com reservas e críticas por lideranças políticas, indígenas e ambientalistas (ÁLVAREZ, 2020).

\footnotetext{
${ }^{39}$ V. também Sullivan, 2017.

40 "Hoje, apenas na porção da Terra Indígena (Yanomami) que ocupa o Estado de Roraima, existem 14 pistas de pouso clandestinas de garimpo ilegal" (ISA, 2019a).

${ }^{41}$ De acordo com a Organização Mundial da Saúde, o mercúrio é um metal de alta toxicidade, sendo substância perigosa para a vida intrauterina e para o desenvolvimento infantil nos primeiros anos de vida. É também capaz de comprometer o sistema nervoso, imunológico, digestivo, respiratório e a visão. A Convenção de Minamata, incorporada ao direito brasileiro, restringe a sua produção e utilização. (MPF, 2020, pp. 173-174).

42 V. Fellet; Costa, 2019. A Rede Amazônica de Informação Socioambiental Georreferenciada (Raisg) identificou garimpos ilegais em 18 terras indígenas no Brasil.

43 "Entre 6 e 7 mil garimpeiros estão retirando ouro ilegalmente na Terra Indígena Yanomami, no norte do país. (...) O garimpo ilegal... explodiu... depois que o Exército desativou as bases de proteção nos Rios Uraricoera e Mucajaí..." (ISA, 2019a).

${ }^{44}$ V. Fellet; Costa, 2019.

45 O Projeto de Lei 191/20 regulamenta a exploração de recursos minerais, hídricos e orgânicos em reservas indígenas. Disponível em: <https://www.camara.leg.br/noticias/634893-projeto-do-governo-viabilizaexploracao-de-minerios-em-terras-indigenas/>. Acesso em 20 fev. 2020.
} 
4. Caça ilegal (Poaching) e tráfico de animais. A caça ilegal e o tráfico de animais silvestres é a terceira ou quarta atividade ilícita mais rentável do mundo, atrás apenas do tráfico de drogas e de armas, e emparelhado com o de pessoas ${ }^{46}$. De acordo com o Forum Econômico Mundial, trata-se de um comércio que movimenta entre 7 e 23 bilhões de dólares por ano (LEHMACHER, 2016). O Brasil, por sua vez, possui uma das maiores diversidades de fauna do planeta. Entre nós, aproximadamente 38 milhões de animais são retirados das florestas e matas por ano, em um negócio que gira mais de 1 bilhão de dólares (BUCHERONI, 2019; RENCTAS, 2019). Operações da Polícia Federal no Amazonas apreenderam, somente em 2018, mais de três toneladas de caça ilegal, centenas de animais terrestres e milhares de peixes ornamentais (INPA, 2018). O tráfico de animais se destina a públicos e objetivos diversos, que incluem: (i) colecionadores particulares, que buscam animais raros ou em extinção; (ii) fins científicos, notadamente a produção de medicamentos; (iii) venda em pet shops, como animais de companhia; e (iv) produção de bens comercializáveis, como couros, peles, cosméticos e souvenirs (BUCHERONI, 2019; RENCTAS, 2019). Além do risco de disseminação de doenças ${ }^{47}$, a retirada de animais do seu habitat natural ameaça espécies de extinção e pode romper o equilíbrio do ecossistema, retirando predadores ou alimento de outras espécies e comprometendo ciclos da natureza ${ }^{48}$. A caça e o comércio ilegais de animais constituem crimes pouco reprimidos e de penas baixas $^{49-50}$.

\section{Outros crimes}

a) Crimes contra os defensores da floresta. O Brasil tem um dos maiores índices de homicídios de defensores da floresta (BRITO et al, 2019, p. 1), aí compreendidos populações indígenas, povos tradicionais da floresta, quilombolas, ativistas de direitos humanos e ambientalistas (VASCONCELLOS, 2019). São vítimas constantes de proprietários de terras (frequentemente "grileiros"), garimpeiros, madeireiros e de pistoleiros de aluguel (GLOBAL WITNESS, 2018). De acordo com a Comissão Pastoral

\footnotetext{
${ }^{46}$ De acordo com o Departamento de Estado dos Estados Unidos. V. Bergman, 2009. Segundo a ONU, em documento de 2014, seria o quarto, após tráfico humano. V. UNODC, 2014.

${ }^{47}$ Como gripe aviária (avian flu) e vírus Ebola, entre outros. V. Can; D'Cruze; Macdonald, 2019; Travis; Watson; 2011.

${ }^{48}$ Por exemplo: "Junto à extinção da fauna, todo o ecossistema sobre com o ciclo do tráfico. A diminuição das espécies predadoras de sementes favorece a dominância de algumas árvores, assim como a ausência de dispersores afeta a reprodução da flora. Dessa forma, toda a estrutura da floresta é alterada". V. Bucheroni, 2019.

${ }^{49}$ No Brasil, a pena base é de 6 meses a 1 ano, e multa. Lei n 9.605/98 (Lei de Crimes Ambientais), art. 29, caput e $\S \S 4$ e e 5 .

${ }^{50}$ Encontra-se em vigor, desde 1973, a Convenção sobre o Comércio Internacional das Espécies da Fauna e da Flora Selvagens em Perigo de Extinção (CITES), que procura regular o comércio de espécies. Nada obstante, não é fácil dar-Ihe cumprimento efetivo e são raras as sanções a países por violação da Convenção. V. Fobar, 2019.
} 
da Terra, ligada à Igreja Católica, foram mais de 300 pessoas assassinadas durante a última década, no contexto dos conflitos pelo uso da terra e dos recursos naturais da Amazônia (HRW, 2019, pp. 3-4). Dois mártires desse embate foram o líder dos seringueiros Chico Mendes, morto em 1988, no Estado do Acre, e a missionária norte-americana Dorothy Stang, vítima de homicídio em 2005, no Estado do Pará.

b) Grilagem de terras. A invasão e ocupação de terras públicas, especialmente em áreas de florestas, tem sido uma constante na Amazônia. Como já descrito, após a extração seletiva da madeira, supressão e queima da vegetação remanescente, áreas públicas são transformadas em pastos e plantações. Em seguida, os grileiros procuram legalizar a posse, dividindo a área em lotes menores, de mais fácil regularização nos termos da legislação, ou simplesmente falsificam títulos e registros de propriedade, com a conivência de cartórios e de agentes públicos (IPAM, 2006). A apropriação privada de terras públicas, à revelia dos órgãos fundiários, como o Instituto Nacional da Reforma Agrária INCRA, assume importante dimensão política, social, econômica e ambiental, tendo em vista que aproximadamente $45 \%$ das terras da Amazônia não foram oficialmente destinadas, seja para assentamentos para fins de reforma agrária seja para a proteção ambiental (IPAM, 2006) ${ }^{51}$. De acordo com dados do Instituto de Pesquisa Ambiental da Amazônia - IPAM, 30\% do desmatamento da Amazônia, entre 10 de janeiro e 20 de agosto de 2019, se deu em terras públicas não destinadas, que são precisamente as áreas visadas pelos grileiros (IPAM, 2019). Em 2001-2002, Comissão Parlamentar de Inquérito da Câmara dos Deputados identificou algumas das finalidades da grilagem: revenda das terras, utilização como garantia para obtenção de financiamentos, dação em pagamento de dívidas previdenciárias e fiscais e obtenção de indenizações nas desapropriações para reforma agrária ou para criação de áreas protegidas (CÂMARA DOS DEPUTADOS, 2001, pp. 353-357). Para completar esse ciclo trágico, de tempos em tempos, o Governo concede anistia a essas invasões e permite a legalização da apropriação privada de terras públicas, como se verá adiante.

c) Biopirataria. Biopirataria é um nome novo para um velho problema, expressão continuada do colonialismo, já agora de índole tecnológica. Ela consiste em atividades e comportamentos diversos, que incluem não apenas a retirada não autorizada de espécies da fauna e da flora, mas, sobretudo, no caso da Amazônia, a apropriação não consentida de conhecimentos tradicionais dos indígenas e povos da floresta. Nesse último caso, procura-se patentear substâncias químicas e

\footnotetext{
${ }^{51} \mathrm{O}$ quadro não se alterou de maneira relevante de lá para cá, embora novas unidades de conservação tenham sido criadas.
} 
princípios ativos originários da região ou cujo conhecimento inicial veio das comunidades locais, privatizando ou monopolizando algo que, ao menos em parte, constitui bem coletivo alheio. Em outros casos, procura-se registrar como marca própria produtos naturais da floresta. Na hipótese de comércio ilegal da fauna, não há dúvida da existência de crime, como visto acima. Não assim, porém, nas situações de aproveitamento dos conhecimentos tradicionais de populações nativas, que não são objeto de tipificação criminal específica ${ }^{52}$. Há diversos exemplos de biopirataria pelo mundo ${ }^{53}$. Em relação à Amazônia brasileira, dois casos se tornaram célebres: a retirada e contrabando de sementes de seringueira, em 1876, que produziu impacto devastador sobre a economia local (ABREU et al, 2019, p. 32); e o registro, no Japão, da marca Açaí, fruta típica da região. O registro veio a ser anulado (FERNANDES, 2017, p. 242). Situação semelhante ocorreu, ainda, com a marca Cupuaçu, que também teve seu registro no mercado internacional desconstituído (NOGUEIRA; SIQUEIRA; SOARES, 2010, pp. $151,152)$. Mais recentemente, vem se consolidando o consenso de que uma das melhores formas de enfrentar a biopirataria é investindo em pesquisa científica e tecnológica local. Adiante se voltará ao ponto.

d) Trabalho escravo, tráfico de pessoas e aliciamento. A escravidão contemporânea no país, especialmente na região da fronteira agrícola amazônica, beneficia-se da escassez de empregos regulares e da existência de um contingente de trabalhadores sem qualificação especial. Uma abordagem recorrente é a utilização por fazendeiros da figura dos "gatos", recrutadores de mão de obra, que aliciam trabalhadores rurais em situação de vulnerabilidade e os levam para regiões remotas $^{54}$. Comumente, a oferta de trabalho oferece benefícios que não correspondem à realidade como garantias de alimentação, salário e alojamento -, convertendo o trabalhador em devedor, por meio da aquisição de produtos e serviços do próprio empregador. Os gatos utilizam, ainda, violência física, moral e confinamento, como formas de manter os empregados em tal condição (OIT, 2011, pp. 16-17; Cacciamali; Azevedo, 2011, pp. 943-948; OIT, 2010, pp. 48-53).

\footnotetext{
52 É certo que a Convenção sobre Diversidade Biológica, de 1992, procurou assegurar a repartição justa e equitativa dos benefícios advindos dos recursos genéticos da diversidade biológica dos países. A convenção, contudo, não tem normas de natureza criminal e seus efeitos práticos ainda são limitados.

${ }^{53}$ Vejam-se, ilustrativamente: (i) a andiroba, árvore amazônica, teve óleo e extrato de seus frutos registrados pela empresa francesa Yves Roche e pela empresa japonesa Masaru Morita; (ii) a copaíba teve patentes registradas pela empresa norte-americana Aveda e pela empresa francesa Technico-flor; (iii) a espinheira santa tem patente de remédio titulada pela japonesa Nippon Mektron; (iv) o jaborandi é objeto de patente registrada pela farmacêutica alemã Merk. V. Fernandes, 2017, p. 242.

${ }^{54} \mathrm{O}$ Código Penal brasileiro tipifica os crimes de trabalho escravo, tráfico de pessoas e aliciamento (arts. 149, 149-A e 207).
} 


\section{REGULARIZAÇÃO DA GRILAGEM, CORRUPÇÃO E IMPUNIDADE}

Como já antecipado, um dos importantes incentivos ao desmatamento na Amazônia vem do próprio Governo, tanto federal - predominantemente - como estadual ${ }^{55}$. A afirmação se refere à dinâmica da invasão-regularização de terras públicas. Para se compreender a questão: as áreas que não são propriedade privada, nem reservas indígenas demarcadas ou unidades de conservação, constituem propriedade pública, também referida como áreas não designadas. Parte dessas áreas públicas correspondem a assentamentos criados pelo Poder Público para fins de reforma agrária, onde foram instalados pequenos agricultores. Aliás, a propósito delas, por falta de fiscalização e cumprimento da legislação, os deveres de preservação não são adequadamente observados e o desmatamento é elevado (IPAM, 2016, pp. 41 e ss.). Porém, a situação mais grave está na "grilagem" de terras, com a ocupação e privatização de áreas públicas da Floresta Amazônica, muitas vezes com violência contra comunidades indígenas ou populações tradicionais. Em relação a isso, há dois problemas nas políticas governamentais. O primeiro é que, por não fiscalizar adequadamente, o Estado permite que essas áreas sejam invadidas, dando início ao ciclo de derrubada da floresta: extração ilegal de madeira, queimada e ocupação do solo. O segundo problema: sob pressão de invasores politicamente respaldados, o Governo Federal, de tempos em tempos, concede anistia e permite a regularização dessa apropriação de terras públicas.

De fato, foi assim com a Lei 11.952/2009, no Governo de Luís Inácio Lula da Silva, com a Lei 13.465/2017, no Governo Michel Temer, e com a Medida Provisória 910, de 11 de dezembro de 2019, editada pelo Presidente Jair Bolsonaro. Aliás, por se opor a essa política, foi exonerado o presidente do Instituto Nacional de Colonização e Reforma Agrária - INCRA (HANBURY, 2019) ${ }^{56}$. Essas leis se inserem na velha lógica brasileira em que as coisas erradas se transformam em fatos consumados e em se seguida se procura legitimá-las. Aliás, mais do que legitimar a apropriação de terras públicas, tais medidas incentivam a continuidade da prática, fomentando o círculo vicioso da invasão, desmatamento e regularização. A nova Medida Provisória, a exemplo da lei anterior, permite a aquisição dessas terras mediante o pagamento de valores bem inferiores aos de mercado, gerando prejuízo para a União de alguns bilhões de reais. Funciona, ainda, como um incentivo à continuidade

\footnotetext{
55 Leis de regularização de terras ocupadas recentemente, mediante pagamento de valores irrisórios, foram aprovadas pelos Estados do Pará, Mato Grosso e Amazonas (BRITO, 2019).

56 “De acordo com a mídia, (o General João Carlos de Jesus) Corrêa foi demitido por ser contra o plano do governo Boslonaro de facilitar o processo de regularização de cerca de 750 mil títulos fundiários" (HANBURY, 2019).
} 
das invasões, já que confirma uma tendência à posterior regularização da propriedade dos invasores (BRITO et al, 2019, p. 2).

Após o episódio do incêndio criminoso de um caminhão de combustível em Espigão do Oeste, o Instituto Brasileiro de Meio Ambiente e dos Recursos Renováveis - IBAMA organizou uma grande operação de reação, para reprimir a extração ilegal de madeira e as serrarias utilizadas por tais madeireiros. Foram reunidos 35 agentes do IBAMA, 50 policiais e cerca de 100 soldados do Exército. Quando o comboio de carros da polícia e caminhões militares estava a caminho, após sair de Porto Velho, um dos agentes, ao acessar a rede social, se deparou com entrevista do líder dos madeireiros discutindo a operação, que era sigilosa. Evidenciou-se que alguém de dentro das instituições responsáveis pela repressão ao desmatamento havia vazado a informação (WALLACE, 2019). Esse é outro dos problemas enfrentados: a corrupção - e politização - de agentes públicos responsáveis pela proteção ambiental e, também, muito intensamente, de notários e oficiais de registro de imóveis, acusados de forjar documentos e registros de propriedade. Também existem queixas relevantes quanto à atuação do Poder Judiciário (CÂMARA DOS DEPUTADOS, 2001, pp. 358-363) ${ }^{57}$.

A impunidade é a regra geral em relação aos crimes associados ao desmatamento da Amazônia. De acordo com relatório da Human Rights Watch, dos mais de 300 assassinatos registrados pela Comissão Pastoral da Terra desde 2009, apenas 14 foram levados a julgamento (HRW, 2019, pp. 5-6). Vale dizer: defensores da floresta, como indígenas, populações locais, ativistas de direitos humanos, ambientalistas, missionários e mesmo agentes do IBAMA são vítimas constantes de crimes que sequer são apurados. De outro lado, notários e registradores responsáveis por escrituras públicas fraudulentas e registros sem título de domínio anterior ou em duplicidade raramente respondem por

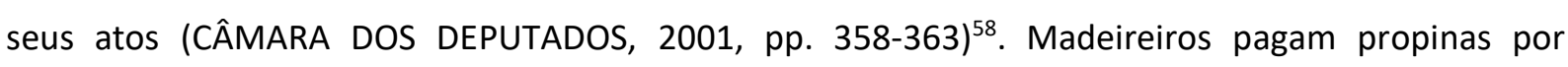
documentos falsos que atestam que a madeira é proveniente de área licenciada e os agentes públicos que recebem essas vantagens ilícitas também costumam escapar dos rigores da lei. Apenas uma ínfima porcentagem das multas aplicadas pelo IBAMA por violações ambientais é efetivamente cobrada e $\operatorname{arrecadada}^{59}$. A tudo isso se somam as leis regularizadoras referidas acima. Nesse quadro dramático

\footnotetext{
${ }^{57}$ Apesar de se tratar de diagnóstico antigo, as patologias continuam as mesmas (BARRETO; MESQUITA, 2009). ${ }^{58}$ Apesar de se tratar de diagnóstico antigo, as patologias continuam as mesmas.

${ }^{59}$ Consta no Portal do Tribunal de Contas da União, no demonstrativo da arrecadação de multas administrativas, entre 2005 e 2009, que menos de $1 \%$ das multas aplicadas pelo IBAMA foram efetivamente recolhidas (Fonte: TCU, 2010). O quadro não se alterou ao longo do tempo. V. Bárbara Libório, 2019.
} 
de leniência do Poder Público, de corrupção e de impunidade, a Floresta Amazônica fica frequentemente indefesa.

\section{O DRAMÁTICO DESGASTE DA POLÍTICA AMBIENTAL BRASILEIRA}

Pesquisas empíricas demonstram que a presença atuante do Poder Público, com pessoal, equipamentos e vontade política, é fator decisivo na contenção do desmatamento. Até porque a destruição florestal apoia-se em práticas ilegais e, com frequência, no "banditismo" (ABRAMOVAY, 2019, p. 11). A redução histórica do desmatamento, ocorrida entre 2004 e 2012, se deveu, sobretudo, à fiscalização severa implementada, com efetiva atuação de campo, envolvendo prisões, apreensões e multas (CAPOBIANCO, 2017, p. 118). Vale dizer: as políticas ambientais de comando e controle foram indispensáveis para interromper o ciclo da violência e da destruição (ABRAMOVAY, 2019, p. 11). Também desempenharam papel relevante o aprimoramento do processo de monitoramento e transmissão de informações - que orientaram as operações de fiscalização -, a criação de unidades de conservação e a demarcação de terras indígenas. Nesse último caso, pelo fato de que as terras inseridas nessas áreas protegidas perdem o valor, na medida em que não é possível obter titulação sobre elas, desestimulando a grilagem (CAPOBIANCO, 2017, p. 120). Pois bem: foi precisamente o afrouxamento da fiscalização que permitiu, a partir de 2013, que o índice de desmatamento voltasse a crescer significativamente.

A situação agravou-se ao longo de 2019, com elevação de 30\%, em contraste com o ano anterior, atingindo a marca de $9.762 \mathrm{Km}^{2}$ (INPE, s/d) ${ }^{6061}$. Organizações ambientais, defensores da floresta e cientistas atribuíram este incremento a atitudes do novo Governo ${ }^{62}$, apontando, em meio a outras queixas, declarações públicas de altas autoridades que sinalizaram desinteresse pela questão ambiental ${ }^{63}$, associadas a atos concretos que implicaram em uma substancial alteração das políticas

\footnotetext{
${ }^{60}$ Notícias anteriores apontavam um volume bem maior. V. AFP, 2020. Deutsche Welle, 2020.

${ }^{61}$ Nas terras indígenas esse aumento foi ainda mais expressivo, no percentual de $80 \%$, quando comparado com 2017-2018 (ISA.a, 2019).

62 "O governo Bolsonaro tem agido de forma agressiva para diminuir a capacidade do país de fazer cumprir suas leis ambientais"; segundo o coordenador da campanha de políticas públicas do Greenpeace Brasil, "o governo tem uma agenda de desmonte e destruição ambiental” (HRW, 2020, p. 10). V. Rosa, 2020; o pesquisador Carlos Nobre afirmou: "A pauta não é mais de interesse, como era desde 1992, com todos os governos que tivemos, com vários partidos políticos".

${ }^{63}$ A título ilustrativo, mencionam-se manifestações do Presidente da República sobre abandonar o Acordo de Paris, extinguir o Ministério do Meio Ambiente, bem como a renúncia do país a sediar, em 2019, a Conferência das Nações Unidas sobre Mudanças Climáticas (COP 25). V., respectivamente: Darby, 2018; Stachewski, 2019; e Vilela, 2018.
} 
públicas necessárias à prevenção e ao controle do desmatamento (ESTADÃO CONTEÚDO, 2019). Tais comportamentos teriam contribuído para aumentar a ousadia de madeireiros, garimpeiros e grileiros no entendimento das organizações ambientais ${ }^{64}$.

Entre os atos antes aludidos, podem-se listar: (i) a extinção da Secretaria de Mudanças do Clima e Florestas do Ministério do Meio Ambiente (MMA) ${ }^{65}$, (ii) a extinção da Subsecretaria Geral de Meio Ambiente, Energia e Ciência e Tecnologia do Ministério das Relações Exteriores ${ }^{66}$, (iii) a exoneração de inúmeros superintendentes estaduais do Instituto Brasileiro do Meio Ambiente (IBAMA $)^{67}$ e sua substituição por pessoas alegadamente descomprometidas com as causas ambientais (FORTE; CARVALHO; RODRIGUES, 2020); (iv) a redução do número de membros do Conselho Nacional do Meio Ambiente (CONAMA), com impacto sobre a representação das organizações não governamentais (ONGs), dos estados e da sociedade civil ${ }^{68}$; $(\mathrm{v})$ a transferência do Serviço Florestal Brasileiro para o Ministério da Agricultura, Pecuária e Abastecimento (Ministério da Agricultura) ${ }^{69}$, ao qual se atribui a defesa de interesse conflitante; (vi) a alteração da competência para demarcar terras indígenas, com sua migração da Fundação Nacional do Índio (FUNAI) para o Ministério da Agricultura ${ }^{70}$; (vii) a manifesta hostilidade em relação às organizações não governamentais que atuam ao lado dos defensores da floresta (HRW, 2019, pp. 5,6); e, por fim, (viii) a extinção do Comitê Orientador do Fundo Amazônia, que detinha a atribuição de estabelecer os critérios e acompanhar a aplicação dos recursos do Fundo ${ }^{71}$. Esse último ato agravou a crise diplomática do Brasil com Alemanha e Noruega, os dois mais importantes financiadores de ações voltadas à proteção ambiental da Amazônia, levando à suspensão de novas doações, após tais países terem destinado bilhões de reais para a causa.

Então, em fevereiro de 2020, aparentemente procurando sinalizar uma mudança de atitude, o Governo transferiu o Conselho Nacional da Amazônia Legal do Ministério do Meio Ambiente para a Vice-Presidência da República. O Conselho tem, entre os seus fins, coordenar os diversos Ministérios

\footnotetext{
64 “Desde janeiro de 2019, o governo federal vem emitindo sinais que são lidos, no plano local, como permissão para o avanço da invasão de terras públicas e freio às ações estatais que procuram combater estas práticas criminosas" (ABRAMOVAY, 2019, p. 13).

65 Decreto no 9.672, de 2 janeiro de 2019.

${ }^{66}$ Decreto no 9.683, de 9 janeiro de 2019.

67 Portarias de no 107 a 127, de 28 de fevereiro de 2019.

${ }^{68}$ Decreto no 9.806, de 28 de maio de 2019.

${ }^{69}$ Decreto no 9.667, de 2 de janeiro de 2019.

70 Medida Provisória no 870, de 10 de janeiro de 2019, convertida na Lei no 13.884, de 18 de junho de 2019. A medida provisória, nessa parte específica, não foi aprovada pelo Congresso Nacional. Tentativa de reeditá-la, por sua vez, foi considerada inconstitucional pelo Supremo Tribunal Federal.

${ }^{71}$ Decreto no 9.759, de 11 de abril de 2019.
} 
e órgãos governamentais que cuidam da questão ambiental, bem como propor políticas e iniciativas relacionadas à preservação, à proteção e ao desenvolvimento sustentável da Amazônia Legal. Será preciso esperar para ver se o país irá conseguir recuperar-se da quebra de imagem mundial nessa matéria e ter sucesso na drástica redução do desmatamento, para que possa voltar ao radar da sociedade a meta desejável do desmatamento líquido zero ${ }^{72}$.

\section{Parte III}

\section{ALGUNS CAMINHOS PARA A PRESERVAÇÃO:}

\section{A floresta vale mais de pé do que derrubada}

\section{O INSUCESSO DOS MODELOS DE DESENVOLVIMENTO ADOTADOS ATÉ AQUI}

Duas formas diametralmente opostas de lidar com a Floresta Amazônica foram adotadas do início dos anos 70 para cá. A primeira se pode cognominar desenvolvimentista, que consiste na derrubada da floresta para ocupação da área com atividades econômicas como pecuária, agricultura, extração de madeira, mineração e usinas hidroelétricas. Essa concepção não leva em conta as consequências graves da destruição do bioma amazônico ${ }^{73}$. A segunda pode ser identificada como ambientalista, por sua ênfase na manutenção da floresta intacta, com a instituição de grandes áreas de proteção, representadas pela demarcação de terras indígenas e pela criação de unidades de conservação (PRESIDÊNCIA DA REPÚBLICA, 2004). Nenhum dos dois modelos foi capaz de extrair as melhores potencialidades econômicas e sociais da Amazônia, cujo PIB representa 8\% do total nacional, com alguns dos piores indicadores sociais do país (VERÍSSIMO, 2015) ${ }^{74}$. A partir de meados dos anos 2000, acreditou-se ser possível uma fórmula híbrida, que conciliasse a exploração de atividades econômicas com a preservação da floresta (PRESIDÊNCIA DA REPÚBLICA, 2004). Nada obstante, as fronteiras de desmatamento continuaram a se expandir (NOBRE et al, 2016, p. 10759). Na quadra atual, vem ganhando força uma ideia referida como terceira via ou Amazônia 4.0, expressões que se

\footnotetext{
72 Decreto no 10.239, de 12 de fevereiro de 2020.

73 Bioma é um espaço geográfico com características próprias de clima, vegetação, fauna, altitude e outros fatores. De acordo como o Ministério do Meio Ambiente, o Brasil é formado por seis biomas diversos: Amazônia, Caatinga, Cerrado, Mata Atlântica, Pampa e Pantanal (MMA, s/d.b).

74 “Em 1970, quando o ritmo de desmatamento na Amazônia começou a realmente acelerar, a região gerava pouco menos de 8 por cento do produto interno bruto do Brasil. Hoje, 45 anos mais tarde, depois de todo o desmatamento ocorrido, depois do surgimento de todas as fazendas de gado e projetos de mineração e centros urbanos, a região amazônica ainda produz os mesmos 8 por cento do PIB brasileiro" (VERÍSSIMO, 2015).
} 
referem ao desenvolvimento de uma economia da floresta, sustentável e justa para as comunidades locais $^{75}$. A seguir são discutidos todos esses modelos.

\section{Modelo desenvolvimentista: derrubada da floresta para exploração de atividades econômicas}

A ocupação efetiva da Amazônia começou em meados da década de 60, impulsionada, principalmente, por uma preocupação geopolítica: a de integrá-la ao território nacional, tornando a área povoada e o Estado presente. $\mathrm{O}$ objetivo subjacente era assegurar a soberania do país sobre a floresta e seus recursos naturais (BECKER, 2001, pp. 135-136). A partir daí, teve início a política de estímulo a produtores e trabalhadores de diversas partes do Brasil para se estabelecerem na região. Para tanto, foram oferecidos incentivos fiscais, facilitação de crédito e terras baratas (MAHAR, 1978, pp. 107-169; ALMEIDA, 1992, pp. 20-25). Estradas passaram a ser abertas para possibilitar o escoamento da produção, com a inevitável consequência da ocupação e do desmatamento de suas margens e do impacto sobre o ecossistema. Aos poucos foi se formando o que hoje é conhecido como o "arco do desmatamento", onde se verifica intensa supressão da floresta, com grandes focos de calor $^{76}$. Em muitas lideranças prevalece, ainda hoje, a crença de que desmatamento é sinônimo de desenvolvimento ${ }^{77}$. É bem de ver, no entanto, que o solo amazônico não é, de modo geral, um solo rico, e depende da cobertura vegetal e do clima para sua própria preservação (NOBRE et al, 2016; MAHAR, 1978, pp. 122-127). Entre as críticas ao processo de integração adotado na Amazônia situamse, além da degradação ambiental, a formação de latifúndios ${ }^{78}$ e a não exigência de que ao menos parte dos ganhos obtidos fosse reinvestido localmente (MAHAR, 1978, pp. 107-169; ALMEIDA, 1992, pp. 122-127).

\footnotetext{
${ }^{75}$ Segundo Beto Veríssimo (2020, pp. 5-6), os ciclos de desenvolvimento da Amazônia podem ser didaticamente resumidos na seguinte tipologia: Amazônia 1.0 (Velho Extrativismo); Amazônia 2.0 (Agropecuária); Amazônia 3.0 (Sistemas agroflorestais e turismo); e Amazônia 4.0 (Bioeconomia e serviços ambientais).

${ }^{76}$ O Arco do Desmatamento - ou Arco de Povoamento Adensado - se estende desde o oeste do Estado do Maranhão, passando por Tocantins, parte do Pará e do Mato Grosso, todo o Estado de Rondônia, o sul do Amazonas chegando ao Acre. Trata-se da região que concentra os maiores índices de desmatamento da Amazônia, aproximando-se de $75 \%$ do total. 0 desenho desse arco foi iniciado pelas rodovias Belém-Brasília e Cuiabá-Porto Velho, e aumentou de tamanho com a expansão das rodovias, que irradiam o desmatamento para o interior da floresta. V. ISA, 2019c.

${ }^{77}$ Confira-se, a esse propósito, declaração de Assuero Doca Veronez, presidente da Federação de Agricultura do Acre: "Desmatamento para nós é sinônimo de progresso, por mais que isso possa chocar as pessoas". E acrescentou: "[O] Acre não tem minério, não tem potencial turístico, o que tem são as melhores terras do Brasil. Só que esta terra tem um problema, uma floresta em cima" (WENZEL, 2020).

${ }^{78}$ Os incentivos fiscais possibilitaram que poucas empresas adquirissem grandes áreas de terras a preços muito baixos e foram responsáveis pela formação de grandes latifúndios com dinheiro público (MAHAR, 1978, p.160).
} 
O fato é que, ao longo do tempo, o agronegócio foi se consolidando como a principal atividade econômica do país (CEPEA, 2020), com participação expressiva da produção advinda da Amazônia. Os números impressionam: o Brasil é o maior exportador de soja do mundo, produzindo em torno de $30 \%$ da oferta total existente (STABILE et al, 2020, p. 1) ${ }^{79}$. Aproximadamente $58,5 \%$ dessa produção é destinada ao mercado internacional, sendo que $12 \%$ se originam no bioma Amazônia (FEBRABAN; FGV EAESP, 2018, pp. 28-36). No tocante à pecuária, o país detém o maior rebanho bovino do planeta e é responsável por aproximadamente $15 \%$ da carne bovina consumida mundialmente (STABILE et al, 2020, p. 1). Pois bem: $40 \%$ dos animais e parte expressiva dos frigoríficos estão localizados na Amazônia Legal (FEBRABAN; FGV EAESP, 2018, pp. 13-37; BARRETO et al, 2017). Cerca de 20\% da produção de carne bovina é destinada ao exterior (FEBRABAN; FGV EAESP, 2018, pp. 13-37) ${ }^{80}$. Estimase que a pecuária seja a principal responsável pelo desmatamento de $80 \%$ das áreas da Amazônia (PRESIDÊNCIA DA REPÚBLICA, 2004, p. 10) ${ }^{81}$. A verdade, porém, é que não existe uma relação necessária entre agronegócio e desmatamento: no período em que a destruição da floresta declinou em 80\% (entre 2004 e 2012), os resultados praticamente triplicaram (NOBRE et al, 2016, p. 10760). E isso não se deveu apenas aos preços do mercado internacional. Além disso, estudos indicam que a produtividade do agronegócio na Amazônia é inferior à alcançada em outras áreas ${ }^{82}$ e que ela pode ser substancialmente aumentada, mantidas as terras já ocupadas, mediante investimento, tecnologia e gestão adequados (STABILE et al, 2020, p. 4).

A lógica econômica que favorece o desmatamento também está presente na população de baixa renda, entre os pequenos produtores e nos assentamentos. Esses grupos sofrem com baixa produtividade, decorrente da falta de infraestrutura básica, do baixo acesso à tecnologia, à assistência técnica e aos mercados. Removem a cobertura de vegetação, promovem queimadas, esgotam o solo e migram em busca de novas áreas. Estima-se que os assentamentos agrícolas são responsáveis por

\footnotetext{
${ }^{79}$ Segundo dados da Organização das Nações Unidas para a Alimentação e a Agricultura (Food and Agriculture Organization of the United Nations - FAO), em janeiro de 2018, a quantidade de grãos de soja produzida pelo Brasil correspondia a $34 \%$ do total de grãos de soja do mundo. Disponível em: <http://www.fao.org/faostat/en/\#compare>. Acesso em 01 abr. 2010.

${ }^{80}$ De acordo com o estudo, $81 \%$ da produção destinam-se ao mercado interno e $19 \%$ são exportados para o mercado externo, tendo como principais destinos, a China, Egito, Rússia e Irã.

${ }^{81}$ Nas palavras do documento: "A pecuária é responsável por cerca de $80 \%$ de toda área desmatada na Amazônia Legal" (PRESIDÊNCIA DA REPÚBLICA, 2004, p. 10). Estudo do Instituto do Homem e Meio Ambiente da Amazônia - IMAZON afirma que "a pecuária continua como a principal ocupação das áreas desmatadas na Amazônia, ocupando de 75\% a 81\% do total desmatado entre 1990 e 2005". V. Barreto; Pereira; Arima, 2008, p. 20.

82 Trabalho de 2016 observa que a produção agrícola da Amazônia representa 14,5\% do produto interno do setor, com a utilização de uma área de $750.000 \mathrm{~km} 2$ de desmatamento; ao passo que São Paulo é responsável por $11,3 \%$ do produto agrícola bruto, valendo-se, para isso, de uma área de aproximadamente $193.000 \mathrm{~km} 2$. (NOBRE et al, 2016, p. 10759).
} 
aproximadamente $30 \%$ do desmatamento nos últimos anos (STABILE et al, 2020, p. 4) ${ }^{83}$. Reduzir o desmatamento, nessa camada da população, depende do desenvolvimento de políticas públicas de assistência à sua produção e/ou da criação de alternativas econômicas que Ihes ofereçam outras oportunidades de renda. Tal como se encontram esses pequenos produtores, a luta é pela sobrevivência e nela prevalece a visão de curto prazo. Ainda que o desmatamento e as queimadas (ou, mesmo, a extração de madeira e o garimpo ilegal) provoquem a exaustação do solo, eles são os instrumentos que permitem a sua subsistência imediata ${ }^{84}$. Nota-se, assim, que há uma lógica econômica na devastação da floresta. Enquanto essa lógica econômica não for enfrentada, a pressão sobre a floresta persistirá.

\section{Modelo ambientalista: ênfase na preservação máxima da floresta}

Em contraste com o anterior, há um segundo modelo de ocupação da Amazônia cujo foco primário é a preservação da floresta, sua fauna, flora, rios, povos e culturas tradicionais. Para tanto, procura-se criar áreas intensamente resguardadas e reguladas, de modo que a maior parte do bioma amazônico esteja protegido perpetuamente. Situa-se nessa lógica a criação de largas unidades de conservação - que incluem parques nacionais, reservas biológicas, florestas nacionais e áreas de proteção ambiental -, bem como a demarcação de terras indígenas. As unidades de conservação, que são reguladas por lei aprovada no ano de 2000, podem ser (i) de proteção integral, que se destinam à manutenção dos ecossistemas livres de quaisquer alterações causadas por interferência humana ${ }^{85}$; e (ii) de uso sustentável, voltadas à exploração dos bens da natureza de maneira a garantir a perenidade dos recursos e processos ecológicos, de forma socialmente justa e economicamente viável ${ }^{86}$. As

\footnotetext{
${ }^{83}$ Em outubro de 2019, 32\% do desmatamento foi registrado em assentamentos. V. IMAZON, 2019.

84 Estudos indicam que a chegada do desmatamento provoca um aquecimento da economia local e oportunidades de trabalho e renda para a população. A esse "boom" segue-se, contudo, uma queda econômica, "bust", indicando que o crescimento produzido pelo desmatamento não se mantém. Um desses estudo observa, contudo, que após a queda, a economia local se recupera parcialmente. De todo modo, o que interessa para o presente trabalho é que o aumento imediato das oportunidades de renda, para comunidades marcadas pela escassez, pode ser suficiente para acionar a lógica do desmatamento. Portanto, é preciso construir alternativas para essas comunidades. V. Celentano; Sills; Salles; Veríssimo, 2012, p. 850-864; e Rodrigues et al, 2009, p. 14351437.

85 Lei n. 9.985/2002, art. 2으, I, e arts. 8 a 13. O grupo das unidades de conservação de proteção integral se compõe de estações ecológicas, reservas biológicas, parques nacionais, monumentos naturais e refúgio de vida silvestre, cada qual com características específicas.

${ }^{86}$ Lei n. 9.985/2002, art. 2º, I, e arts. 14 a 21. O grupo das unidades de conservação de uso sustentável se compõe pelas seguintes espécies: área de proteção ambiental, área de relevante interesse ecológico, floresta nacional, reserva extrativista, reserva de fauna, reserva de desenvolvimento sustentável e reserva particular do patrimônio natural.
} 
unidades de conservação resguardam o habitat e o modo de vida dos povos tradicionais da floresta, protegem a biodiversidade e preservam o potencial econômico do bioma amazônico.

Já as terras indígenas pertencem formalmente à União, mas, nos termos da Constituição, os "índios" têm direitos originários sobre as áreas que tradicionalmente ocupam, competindo ao Governo federal demarcá-las e protegê-las ${ }^{87}$. De ordinário, os povos indígenas desenvolvem um uso compatível com sua cultura tradicional, que valoriza o aproveitamento sustentável dos recursos naturais e a proteção da natureza. Como já assinalado, a exploração de recursos hídricos e do potencial energético, bem como a pesquisa e lavra de riquezas minerais em terras indígenas dependem de autorização do Congresso Nacional, da oitiva das comunidades interessadas e da garantia de sua participação nos resultados ${ }^{88}$. A criação de tais áreas constitui um obstáculo ao avanço descontrolado da atividade econômica. Em dados de 2019, as terras indígenas somavam 723 áreas, sendo 424 delas na Amazônia. Em termos de extensão, 98\% dessas áreas estão na Amazônia Legal, representando 23\% do seu território (PIB, 2019). A demarcação de terras indígenas legitimamente ocupadas pelas populações nativas tem um componente de justiça imanente e outro utilitarista: preserva a vida de tais povos, resguarda direitos que veem de tempos imemoriais e contribui para a preservação ambiental, que beneficia toda a humanidade. Nada obstante, há críticos severos das políticas públicas de demarcação ${ }^{89}$.

Em 2004, diante do avanço sobre a floresta e sob pressão internacional, o Brasil lançou o Plano de Ação para Prevenção e Controle do Desmatamento na Região Amazônica (PPCDAm) (MMA, 2016b), tendo por objetivos declarados reduzir de forma contínua e consistente o desflorestamento e criar as condições para se estabelecer um modelo de desenvolvimento sustentável na Amazônia Legal. O Plano foi estruturado em quatro fases, articuladas em torno de quatro eixos: (i) ordenamento fundiário e territorial; (ii) monitoramento e controle ambiental; (iii) fomento às atividades produtivas sustentáveis; e (iv) instrumentos econômicos e normativos. Na primeira fase do PPCDAm, entre 2004 e 2008, o eixo da ordenação fundiária e territorial logrou o maior êxito, com a criação de mais de 25 milhões de hectares de unidades de conservação federais e a homologação de 10 milhões de hectares de terras indígenas (MMA, s/d.a) ${ }^{90}$. Na segunda fase, de 2009 a 2011, o eixo monitoramento e controle

\footnotetext{
${ }^{87}$ Constitução Federal, art. 231.

${ }^{88}$ Constituição Federal, art. 232.

${ }^{89}$ Entre eles, o atual Presidente da República, Jair Bolsonaro. V. Oliveira, 2020.

90 Também os Estados-membros da região contribuíram com outros 25 milhões de hectares de unidades de conservação.
} 
foi o grande responsável pela queda das taxas de desmatamento, em virtude da eficiência do sistema de monitoramento e da agilidade das ações integradas de fiscalização e de combate ao crime organizado, levadas a efeito pelo IBAMA, Polícias Federal e Rodoviária, Força Nacional de Segurança Pública e apoio do Exército (MMA, s/d.a). Em 2009, foi aprovada, ainda, a Política Nacional sobre Mudança do Clima (PNMC), por meio da qual o Brasil adotou o compromisso nacional voluntário de redução entre $36,1 \%$ e $38,9 \%$ das suas emissões de carbono projetadas até $2020^{91}$.

Embora todos os quatro eixos devessem ser implementados simultaneamente, as duas primeiras fases do PPCDAm se alinharam ao modelo ambientalista de ênfase na preservação da floresta.

\section{O modelo híbrido: o difícil equilíbrio}

O terceiro eixo do PPCDAm - fomento às atividades produtivas sustentáveis -visa ao desenvolvimento de atividades econômicas compatíveis que se compatibilizem com a preservação de um meio ambiente equilibrado. Trata-se de um meio termo que procura não ser indiferente às necessidades econômico-sociais dos produtores e trabalhadores da região, mas que não descura da necessidade premente de proteção da floresta. Como assinalado, as duas primeiras etapas do Plano foram bem-sucedidas na contenção do desmatamento. Em decorrência, intensificaram-se as demandas por alternativas econômicas para a população, já que a contenção das atividades ilícitas acaba resultando em algum grau de desestruturação dos seus meios de subsistência. O próprio relatório de avaliação da implementação da terceira etapa (2012-2015) constatou o êxito do plano na redução do desmatamento, mas ressalvou que o eixo de ações para o desenvolvimento sustentável havia obtido um grau baixo de sucesso e que esse é um capítulo essencial para que o esforço na promoção do desmatamento persista no tempo (CEPAL; IPEA; GIZ, 2011). Não por acaso, a partir de 2015, com o desaquecimento da economia do país, os níveis de desflorestamento voltaram a crescer, seguindo em ritmo progressivo nos anos de 2016, 2017 e 2018. Em 2019, o aumento foi de 30\% em relação ao ano anterior ${ }^{92}$, alcançando inclusive terras indígenas e unidades de conservação (INPE, 2019).

\footnotetext{
91 Lei n. 12.187/2009, art. 12.

92 Instituto Nacional de Pesquisa Espaciais - INPE. PRODES - Amazônia: Monitoramento do Desmatamento da Floresta Amazônica Brasileira por Satélite. Disponível em: <http://www.obt.inpe.br/OBT/assuntos/programas/amazonia/prodes>.Acesso em 1 mar. 2020.
} 
As principais categorias fundiárias da Amazônia, relativamente às áreas públicas, são as unidades de conservação, as terras indígenas, os assentamentos da reforma agrária e as chamadas áreas ou glebas não destinadas. Nas áreas de titulação privada, de modo geral, o que se impõe é o respeito à reserva legal e às áreas de preservação permanente. Já as principais atividades econômicas da região são pecuária, agricultura e extrativismo, aí incluída a produção de madeira. O que está em questão é compatibilizar tais atividades com a preservação da floresta e do meio ambiente em geral. Para tanto, na terceira fase do PPCDAm, o foco no fomento às atividades econômicas sustentáveis tinha por propósito: (i) promover a viabilidade das cadeias produtivas (supply chain) que constituem alternativas ao desmatamento ${ }^{93}$; (ii) fomentar boas práticas agropecuárias, incluindo a substituição do uso do fogo; (iii) aumentar a produção e comercialização de madeira por meio de manejo florestal sustentável, com ampliação das concessões; e (iv) promover atividades produtivas sustentáveis nos assentamentos e na agricultura familiar (MMA, 2013, p. 71). Por ser a agropecuária a principal atividade econômica e principal motor do desmatamento, torna-se particularmente importante a melhoria da produtividade por hectare ${ }^{94}$ e a recuperação de pastos e de superfícies degradadas, com o que se evita a pressão sobre a floresta para abertura de novas áreas para criação ou cultivo. Segundo estudiosos, quase $70 \%$ dos espaços desmatados são subutilizados e existem alguns milhões de hectares abandonados. Com o uso de tecnologia, a terra que foi desmatada é mais do que suficiente para sustentar, pelas próximas décadas, fazendas, mineração e mesmo empreendimentos hidrelétricos (VERÍSSIMO, 2015, p. 3).

Incentivo a atividades sustentáveis (com regularização fundiária, assistência técnica e acesso a meios tecnológicos), conscientização quanto aos efeitos maléficos do fogo (empobrece o solo no longo prazo, emite gases estufas e causa incêndios florestais), melhor aproveitamento do solo, recuperação de áreas degradadas e reocupação de terras abandonadas são alguns instrumentos, ao lado de monitoramento, fiscalização e repressão, que podem ser utilizados para conter o desmatamento na Amazônia. Porém, como demonstram os dados acima, o modelo híbrido não foi capaz de conter a lógica econômica da destruição. A preservação da floresta, portanto, vai exigir, além de todos os esforços descritos até aqui, soluções ousadas, criativas, originais, que demandam, entre

\footnotetext{
${ }^{93}$ Cadeias produtivas são a soma das operações de obtenção e comercialização de uma matéria prima até que chegue ao usuário final. Na produção agrícola, ela é composta das seguintes etapas: aquisição de insumos e sementes, plantio, cultivo, colheita, transporte, armazenamento, beneficiamento e comercialização. V. Vial; Sette; Selito, 2009.

${ }^{94} \mathrm{~A}$ pecuária ainda apresenta baixa produtividade e baixo aproveitamento. A taxa média de lotação da pecuária na Amazônia ainda é muito baixa, entre 0,5 e 1,0 animal por hectare (MMA, 2013, p. 65).
} 
outras coisas, valorização dos conhecimentos tradicionais locais e investimento pesado em ciência e tecnologia.

\section{UM NOVO MODELO DE DESENVOLVIMENTO: A QUARTA REVOLUÇÃO INDUSTRIAL E A BIOECONOMIA DAFLORESTA}

Ao longo do tempo, a Amazônia experimentou atividades econômicas de baixo impacto ambiental, como a produção florestal não madeireira - açaí, babaçu, borracha, castanha do Brasil - e de alto impacto, como agronegócio, extração de madeira e mineração. A verdade é que não houve mudança significativa no patamar econômico, social e humano da região, embora a devastação da floresta tenha chegado próxima a $20 \%$ da área total. Diante desse quadro, cientistas dedicados ao estudo da Amazônia têm procurado desenvolver novas ideias para velhos desafios, apostando na combinação da sociobiodiversidade com novas tecnologias.

Cabe aqui recapitular que o mundo atravessou, até o final do século $X X$, três grandes revoluções industriais: a primeira delas é simbolizada pelo uso do vapor; a segunda, pela eletricidade; e a terceira, pela internet, a rede mundial de computadores, conectando bilhões de pessoas pelo mundo em tempo real ${ }^{95}$. Já agora está em curso a quarta revolução industrial (SCHWAB, 2017; SCHWAB, 2015), produto da fusão da tecnologia da informação e da biotecnologia, num mundo marcado pelo avanço da inteligência artificial e seus desdobramentos, como internet das coisas, drones, carros autônomos, robótica, nanotecnologia, impressão em 3-D, entre muitos outros avanços. A aplicação dessas inovações, invenções e modernidades para desenvolver um novo modelo econômico para a Amazônia tem sido apontada como o caminho do futuro e a redenção para a região.

A bioeconomia é um modelo econômico que prioriza a sustentabilidade. Ela se funda em inovações no campo da tecnologia e das ciências biológicas, com vistas a diminuir a dependência de recursos não renováveis e a viabilizar processos produtivos e industriais de baixo carbono e baixo impacto ambiental (OECD, 2009) ${ }^{96}$. A grande transformação ocorreu quando se tornou possível ler e copiar o código da vida - o DNA -, e também editá-lo (HARVARD BUSINESS REVIEW-BRASIL; CNI, 2013, p. 6). Hoje, técnicas envolvendo a biologia genética estão presentes em domínios diversos, que vão de

\footnotetext{
${ }^{95}$ V. Barroso, 2019, p. 1277.

96 "De uma ampla perspectiva econômica, a bioeconomia se refere ao conjunto de atividades econômicas relacionadas à invenção, desenvolvimento, produção e uso de produtos e processos biológicos" ( "From a broad economic perspective, the bioeconomy refers to the set of economic activities relating to the invention, development, production and use of biological products and processes"). (OECD, 2009)
} 
terapias e fármacos a cultivos agrícolas, rações animais, combustíveis, couros, vacinas, plásticos e uma variedade de produtos. A linguagem do mundo, que já migrara do analógico para o digital, chega agora ao código genético HARVARD BUSINESS REVIEW-BRASIL; CNI, 2013, p. 8). Surge, assim, um novo paradigma para o desenvolvimento sustentável, baseado na bioeconomia. A aplicação desse novo paradigma à Amazônia, aliando o conhecimento da biodiversidade da região às possibilidades da Indústria 4.0, tem sido defendida pelo aclamado climatologista brasileiro Carlos Nobre, em publicações no Brasil e no exterior, assim como em apresentação no Forum Econômico Mundial de 2020, em Davos. O parágrafo que se segue traz a síntese de algumas de suas ideias.

Após a contenção relativa do desmatamento, notadamente entre 2004 e 2012, abriu-se uma janela de oportunidade para estruturar uma "terceira via" de desenvolvimento para a Amazônia, entre os dois extremos representados por manter a floresta intocada ou continuar a derrubá-la. Trata-se da bioeconomia da floresta, que consiste em utilizar o conhecimento propiciado pelas ciências, pela tecnologia, pela inovação e pelo planejamento estratégico para a elaboração de novos produtos farmacêuticos, cosméticos e alimentos, bem como para a pesquisa de novos materiais e soluções energéticas. Exemplo: as plantas da Amazônia contêm segredos bioquímicos, como novas moléculas, enzimas, antibióticos e fungicidas naturais, que podem ser sintetizados em laboratório e resultar em produtos de valor agregado ${ }^{97}$. Também há exemplos de frutos típicos, entre os quais se destacam o açaí e o cupuaçu (NOBRE; NOBRE, 2019, pp. 8-13, 15; NOBRE et al, 2016, pp. 10759-10760, 10764-

10765). Ambos já foram objeto de tentativas indevidas de apropriação dos seus nomes e usos ${ }^{98}$. Aliás, o açaí tornou-se um item importante da pauta de exportação brasileira, cuja produção beneficia mais de 300 mil agricultores e gera, anualmente, mais de 1 bilhão de dólares para a economia da região. É nesse contexto que se concebe o conceito de Amazônia 4.0, que visa agregar às potencialidades da sociobiodiversidade amazônica - fauna, flora e conhecimentos tradicionais - as novas tecnologias e possibilidades da quarta revolução industrial. A ideia é transformar os recursos naturais em produtos de maior valor agregado, gerados e consumidos de forma sustentável. Todo esse processo deve ter a justa preocupação de trazer benefícios substanciais para as comunidades locais (NOBRE; NOBRE, 2019, p. 8-13, 15; NOBRE et al, 2016, pp. 10759-10760, 10764-10765).

\footnotetext{
${ }^{97}$ No mesmo sentido, Thomas Lovejoy: "Todas as espécies desse sistema incrivelmente biodiverso representam soluções para um conjunto de desafios biológicos - cada um deles com potencial transformador e que pode gerar benefícios para toda a humanidade". ("Every species in this incredibly biodiverse system represents solutions to a set of biological challenges -- any one of which has transformative potential and could generate global human benefits"). (WORLD BANK, 2019).

${ }^{98}$ Como já lembrado anteriormente, além do caso do açaí, também o cupuaçu teve o seu nome e seu uso objeto de registro em marcas e patentes, no Japão, nos Estados Unidos e na União Europeia. Posteriormente, tais registros foram descontituídos. V. Nogueira; Soares, 2010, p. 7.
} 
Como intuitivo, tudo o que se expôs até aqui envolve educação, ciência, tecnologia e atração de recursos humanos para a região, vindos de outras partes do Brasil e também de grandes centros internacionais. Gente que possa se juntar ao esforço que de longa data desenvolvem instituições privadas e públicas como INPA - Instituto Nacional de Pesquisas da Amazônia, ISA - Instituto Socioambiental, INPE - Instituto Nacional de Pesquisas Espaciais, IMAZON - Instituto do Homem e Meio Ambiente da Amazônia e CENSIPAN - Centro Gestor e Operacional do Sistema de Proteção da Amazônia e muitas outras. É justamente essa limitação local para a geração de conhecimento, em razão do baixo investimento e do consequente número reduzido de centros de pesquisa e pesquisadores, que dificulta a exploração das potencialidades aqui descritas ${ }^{99}$. Sempre lembrando que vivemos em um mundo no qual conhecimento, informação e tecnologia são os principais ativos. A grande meta, portanto, deve ser produzir conhecimento de ponta e transversal, em áreas como tecnologia digital, ciências biológicas, estudos genéticos, desenvolvimento de matérias primas e outras. Financiamentos governamentais, start ups, novos centros de pesquisa, parcerias públicoprivadas, empreendedores sociais e privados, investidores e empresas poderão contribuir para que ocorra algo assemelhado ao que se passou no Vale do Silício, na Califórnia. Ciência de ponta para enfrentar grandes problemas (NOBRE et al, 2016, p. 10765) ${ }^{100}$. Parece ambicioso demais? Mas, afinal, se a Amazônia é vital para a humanidade, porque nos acomodarmos com um patamar baixo? A esse propósito, documento divulgado no final de 2019 por um grupo de cientistas brasileiros e estrangeiros incluiu entre suas propostas o estabelecimento de um Painel Científico para a Amazônia - PCA (Science Panel for the Amazon - SPA), composto por pesquisadores do setor público e da academia, dos países amazônicos e do resto do mundo. O painel também deverá ter, segundo o documento, a participação de representantes das culturas locais, detentores de conhecimentos tradicionais da floresta (SCIENTISTS OF THE AMAZON COUNTRIES AND GLOBAL PARTNERS, 2019, p. 11).

Em suma: a maior proteção contra a destruição da floresta é que haja maior racionalidade econômica em preservá-la do que em destruí-la, quer porque a sua preservação gera renda para a população, quer porque gera resultados econômicos substanciais de que o país não pode prescindir ou, ainda, porque gera avanços biotecnológicos que aproveitam a toda a humanidade.. Quando esse

\footnotetext{
99 "[G]ostaria de lembrar, antes de mais nada, que a Amazônia contribui com aproximadamente $8 \%$ do PIB brasileiro, mas recebe apenas $2 \%$ dos investimentos em ciência e tecnologia do total aplicado no país" (VAL, 2010, p. 32) .

100 "Tornou-se vital e de fato urgente instigar uma verdadeira revolução científica, de alta tecnologia e inovação na Amazônia". ("It has become vital and indeed urgent to instigate a real scientific, high-tech, and innovation revolution in the Amazon") (NOBRE et al, 2016, p. 10765).
} 
objetivo for alcançado, a floresta estará mais segura. Se esse objetivo não for alcançado, não haverá aparato repressivo capaz de conter a sua destruição.

\section{A PARTICIPAÇÃO INTERNACIONAL}

A participação internacional também pode ser um fator importante na contenção do desmatamento e na sustentabilidade da economia da Amazônia. Em primeiro lugar, os países hoje desenvolvidos devem reconhecer sua responsabilidade histórica pela destruição de suas próprias florestas, bem como sua expressiva contribuição para a mudança climática. Assim sendo, é de justiça que colaborem com os países em desenvolvimento para que não sigam o mesmo caminho, mediante financiamento de programas e projetos que reduzam a emissão de gases de efeito estufa, bem como prestando a assistência técnica necessária. Em segundo lugar, é fato que boa parte da produção agrícola, pecuária, madeireira e mineral da Amazônia destina-se ao mercado de consumo internacional. Logo, esse mercado pode influenciar o comportamento dos produtores domésticos, exigindo práticas sustentáveis de produção. Finalmente, em terceiro lugar, o mercado financeiro internacional pode dar sua colaboração, incorporando a lógica ambiental em suas análises de risco e viabilidade relativamente aos empreendimentos que busquem financiamento ou colocação de ações no mercado. Passa-se, a seguir, ao exame dessas três possíveis vertentes da participação do mercado internacional no combate ao desmatamento.

\section{Financiamento e assistência técnica para redução do desmatamento: MDL e REDD+}

Duas iniciativas se destacam no que diz respeito ao financiamento e à assistência técnica a países emergentes para a promoção do desenvolvimento sustentável. A primeira é o Mecanismo de Desenvolvimento Limpo (MDL), que remonta à Convenção Quadro e ao Protocolo de Kyoto. Por esse instrumento, previu-se que os países desenvolvidos prestariam assistência a projetos de redução de emissões de países em desenvolvimento. Estabeleceu-se que esses projetos gerariam reduções certificadas de emissão (RCE), que poderiam ser negociadas no mercado global, de modo a levantar recursos para a preservação ambiental. O MDL tinha aplicabilidade prevista até 2020. Foi, contudo, alvo de diversas críticas, entre as quais a sua impropriedade para efetivamente lograr impactos ambientais efetivos, já que os países desenvolvidos os usavam justamente para seguir emitindo gases acima do limite (NARAIN; VAN'T VELD, 2008; SUBBARAO; LLOYD, 2011, p. 1600; MICHAELOWA; JOTZO, 2001, p. 511). 
A segunda iniciativa, que parece destinada a substituir o MDL, é o sistema de Redução de Emissões por Desmatamento e Degradação Ambiental (REDD+) $)^{101}$. Trata-se de um mecanismo voltado à capacitação e ao financiamento de projetos de redução de desmatamento ou de recuperação de florestas em países em desenvolvimento, por meio do qual se prevê o pagamento de uma compensação a tais países por seu desempenho na consecução desses objetivos ${ }^{102}$. Esse instrumento foi incorporado pelo Acordo de Paris, pelo qual os países desenvolvidos foram instados a aportar, em seu conjunto, 100 bilhões de dólares ao ano para financiar ações de REDD+, de modo a ajudar os países emergentes a alcançarem as metas de redução de emissões de gases estufa (UN, 2015). No âmbito internacional, duas inciativas importantes de financiamento do REDD+ foram os fundos lançados pelo Banco Mundial (World Bank Forest Carbon Partnership Facility - FCPF) e o UN-REDD Programme, projeto conjunto da Organização das Nações Unidas com a Food and Agriculture Organization (RECIO, 2019, p.132). Alguns países desenvolvidos também lançaram programas bilaterais de apoio ao REDD+, como a Noruega e a Alemanha. Entretanto, o financiamento para ações de REDD+ disponível hoje é insuficiente para as ações de redução (REClO, 2019, p.132): predominam os recursos estatais em montantes limitados e fala-se na necessidade de criar incentivos para que o mercado privado também contribua com recursos (VIANA, 2009).

Em 2008, o Brasil criou o Fundo Amazônia ${ }^{103}$, voltado ao financiamento de ações de REDD+, e que, até o fim de 2018, havia recebido aproximadamente $\mathrm{R} \$ 3,4$ bilhões em doações ${ }^{104}$. Esse montante é composto por $93,8 \%$ de recursos provenientes do governo da Noruega, 5,7\% do governo da Alemanha e 0,5\% da Petróleo Brasileiro S/A - Petrobrás (BNDES, 2019, p. 27-31). Em 2009, o país

\footnotetext{
${ }^{101}$ Há um elemento central que diferencia o REDD+ do MDL. No âmbito do Acordo de Paris, todos os países têm uma meta própria de redução das emissões globais a alcançar; ao passo que, na sistemática do Protocolo de Kyoto, os países desenvolvidos tinham uma meta predefinida e buscavam créditos de carbono nos países em desenvolvimento de modo a flexibilizá-la. (GREINER et al, jun. 2019).

${ }^{102}$ O REDD constituía, originalmente, um mecanismo destinado à diminuição do desmatamento e da degradação florestal (REDD). Mais tarde, incluíram-se em seu escopo o manejo sustentável de florestas, a conservação e o aumento dos estoques de carbono florestal (REDD+).

${ }^{103}$ Decreto n. 6.527/2008. O Fundo tem por objeto o financiamento de ações de prevenção, monitoramento e combate ao desmatamento e de promoção da conservação e do uso sustentável da Amazônia Legal.

104 Criou, ainda, em 2009, o Fundo Nacional sobre Mudança do Clima (Lei 12.114/2009), de natureza contábil, vinculado ao Ministério do Meio Ambiente, voltado ao financiamento de projetos, estudos ou empreendimentos que visem à mitigação da mudança do clima e à adaptação à mudança do clima e aos seus efeitos. Outros instrumentos de financiamento são o Fundo Nacional do Meio Ambiente (Lei no 7.797/1989), o Fundo Nacional de Desenvolvimento Florestal (Lei no 11.284/2006) e o Fundo de Áreas Protegidas do Programa de Áreas Protegidas da Amazônia.
} 
aprovou sua já mencionada Política Nacional sobre Mudança do Clima (PNMC) ${ }^{105}$. Em 2010, assumiu, ainda, o compromisso com a redução de $80 \%$ dos índices de desmatamento da Amazônia Legal, com relação à média verificada entre 1996 e $2005^{106}$. Em 2015, estabeleceu sua Estratégia Nacional para REDD+ (ENREDD+) (MMA, 2016a) e criou a Comissão Nacional para REDD+ (CONAREDD+) ${ }^{107}$. Em decorrência disso, o Fundo Amazônia tornou-se elegível para acesso a pagamentos por resultados REDD+ alcançados pelo Brasil e reconhecidos pela UNFCCC. A história do país vinha sendo, portanto, uma história bem-sucedida na captação de recursos e na construção de credibilidade quanto à sua capacidade de gestão e utilização dos mesmos. Entretanto, o grande aumento do desmatamento na região amazônica em 2019, as queimadas e os desentendimentos com o governo federal conduziram à suspensão dos repasses de valores pelos países referidos (NEGRÃO, 2019; BARBOSA, 2019).

\section{Exigência dos mercados consumidores: produtos não associados ao desmatamento}

Uma segunda contribuição importante para a preservação da Amazônia pode vir dos mercados consumidores das exportações brasileiras. Como já mencionado, uma porção bastante significativa da produção agrícola e pecuária do país é destinada ao mercado internacional, com impacto relevante sobre o PIB. Diante dessa realidade, restrições por parte dos consumidores estrangeiros a produtos associados ao desmatamento podem ser eficazes para desincentivar comportamentos ambientalmente nocivos. E, de fato, uma experiência muito bem-sucedida, conhecida como Moratória da Soja, comprova o ponto. Em 2006, o Greenpeace promoveu uma campanha denunciando nominalmente empresas da indústria da soja - responsáveis pela assistência técnica, financiamento e compra da produção - como cúmplices do desmatamento da Amazônia (GREENPEACE INTERNATIONAL, 2006). A partir daí, teve início a negociação que resultou em um pacto entre as entidades da agroindústria, ONGs ambientais e o próprio Governo no sentido da não aquisição da soja proveniente de áreas desmatadas após julho de 2006. As grandes empresas da indústria cederam diante do risco de danos reputacionais perante um mercado consumidor crescentemente consciente das questões ambientais. Estudos demonstram a queda vertiginosa do desmatamento relacionado à produção dessa commodity (GIBBS et al, 2015, p. 377).

\footnotetext{
105 Lei n. $12.187 / 2009$.

${ }^{106}$ Decreto n. 7.390/2010, art. 6ㅇ, §1으, I. Atualmente, a previsão consta do Decreto n. 9.578/2018, art. 19, §1으, inc. I, que consolidou os atos normativos acerca do Fundo Nacional sobre Mudança do Clima.

107 Decreto n. 8.576/2015 (substituído pelo Decreto n. 10.144/2019, atualmente em vigor).
} 
A inciativa serviu, ainda, de modelo para a celebração de acordo semelhante com grandes empresas produtoras e exportadoras da carne brasileira alguns anos mais tarde. Esse segundo acordo, celebrado com o Greenpeace, ficou conhecido como G4 Zero Cattle Aggrement. Por meio dele, essas empresas se comprometeram com o desmatamento zero em sua cadeia de fornecedores ${ }^{108}$. Um estudo sobre o impacto do acordo na atividade pecuária constatou que ele efetivamente provocou redução do desmatamento por parte dos fornecedores diretos dessas empresas (GIBBS et al, 2016, pp. 32-42). As duas iniciativas demonstram que o mercado de consumo de um produto pode interferir sobre o seu modelo de produção e estabelecer incentivos para que se torne ambientalmente responsável ${ }^{109}$. Não basta, contudo, que apenas os fornecedores diretos sejam monitorados. É preciso controlar toda a cadeia de produção, para evitar que os fornecedores envolvidos com desmatamento vendam para os que estão regulares, "lavando" o produto contaminado. O não monitoramento dos fornecedores indiretos pode produzir mera aparência de engajamento no combate ao desmatamento (FEBRABAN; FGV EAESP, 2018, pp. 32-36). Um dos instrumentos habitualmente utilizados em tal monitoramento é a certificação (NEPSTAD; STICKLER; ALMEIDA, 2006, p. 1600). De todo modo, as experiências antes narradas demonstram a efetividade das ações de controle sobre a cadeia de fornecimento. Embora haja iniciativas internacionais nesse sentido, é preciso reforçá-las, impor o monitoramento de fornecedores indiretos, tornar crível a possível restrição aos produtos comprometidos com desmatamento e sancionar os fornecedores irregulares ${ }^{110}$.

\section{Critérios para as instituições financeiras: o desmatamento como fator de depreciação e risco}

A mesma lógica é aplicável ao mercado financeiro. Os atores financeiros podem contribuir para reforçar o modelo predatório de produção atualmente existente, se se comportarem com indiferença quanto à questão ambiental, ou podem ser agentes de uma grande mudança de paradigma. $\mathrm{O}$ agronegócio depende de recursos para financiar sua produção. Esses recursos podem ser levantados de muitas formas: por meio de financiamentos, venda de participações acionárias, abertura de capital ou outros instrumentos. As instituições financeiras influenciam as decisões sobre

\footnotetext{
${ }^{108} \mathrm{~A}$ iniciativa foi antecedida por ações criminais deflagradas pelo Ministério Público Federal contra pecuaristas e frigoríficos envolvidos com desmatamento. Tais processos e a repercussão do fato conduziram à celebração de Termos de Ajustamento de Conduta por parte dos frigoríficos, por meio dos quais eles se comprometeram a monitorar sua cadeia de fornecedores e a não adquirir carnes daqueles que estivessem envolvidos com desmatamento. V. NWF; GLUE, s/d.

${ }^{109}$ No mesmo sentido, Nepstad et. al, 2014; Brannstrom et al, 2012.

${ }^{110}$ A título ilustrativo, para iniciativas internacionais nesse sentido, v. ações do Consumer Goods Forum (CGF), da Tropical Forest Aliance (TFA), bem como a NY Declaration on Forests e a Amsterdam Declaration Partnership. V. NWF; GLUE, s/d.
} 
investimentos e os modelos de negócio, ao levarem ou não em conta o critério ambiental em suas decisões (FICHTNER; HEEMSKERK; GARCIA-BERNARDO, 2017). Nesse sentido, vale assinalar que há uma compreensão crescente de que os investimentos financeiros podem ser adversamente afetados por problemas ambientais ou por danos reputacionais decorrentes de empresas envolvidas com desmatamento (GALAZ et. al, 2015). Basta considerar, por exemplo, a possibilidade de restrição aos pertinentes produtos pelos respectivos mercados de consumo, tratada no item anterior. Cogita-se, ainda, da alternativa de responsabilizar as instituições financeiras que patrocinem atividades ilícitas (SCHOLTENS, 2017).

Algumas instituições financeiras já passaram a adotar a análise de risco ambiental em seus investimentos. É o caso do Banco da Noruega, que excluiu de seu portfolio as companhias que não se ajustaram a determinados standards ambientais (GALAZ et. al, 2015). Na mesma linha, a International Finance Corporation, braço financeiro do Banco Mundial, incluiu o aspecto ambiental em seus critérios de medição de performance (GALAZ et. al, 2015). Esse tipo de preocupação tampouco é estranho às instituições financeiras brasileiras. De fato, existem parâmetros de verificação da regularidade ambiental para fins de financiamento agropecuário e exigências específicas para empresas que integram o bioma Amazônia (FEBRABAN; FGV EAESP, 2018, pp. 52-67). Também aqui, o exame dos atores financeiros não deve se ater à empresa financiada ou a seus fornecedores diretos. Precisam ter em conta toda a cadeia produtiva, considerar também os fornecedores indiretos e estabelecer standards de conformação e de boas práticas, que, se não atendidos, ensejem a rejeição do financiamento ou a aplicação de penalidades.

Mesmo os produtores mais resistentes à questão ambiental respondem a incentivos econômicos. Caso a regularidade ambiental de toda a sua cadeia se torne uma condição sem a qual não lograrão financiar a sua atividade, a tendência é de que venham a ajustar seu comportamento a essa nova realidade. Portanto, uma terceira possibilidade de participação internacional no combate ao desmatamento na Amazônia é o estabelecimento de standards globais de performance ambiental a serem levados em conta pelas instituições financeiras para a avaliação da abertura de capital, da aquisição de participação acionária, do financiamento ou de qualquer outro negócio que evolva agentes que tenham, em sua cadeia de fornecedores, empresas atuantes no bioma da Amazônia. Ainda que os standards não sejam obrigatórios, seu reconhecimento como boas práticas e a adesão 
de instituições podem criar importantes incentivos reputacionais e contribuir para a construção de um novo paradigma ambiental ${ }^{111}$.

\section{CONCLUSÃO}

A mudança climática, o aquecimento global e a extinção de espécies constituem desafios ameaçadores do nosso tempo, com graves implicações para o futuro da humanidade. A Amazônia desempenha um papel crítico no enfrentamento desses problemas e no equilíbrio ecológico do planeta, por sua extraordinária biodiversidade, por sua função no ciclo da água e no regime de chuvas, bem como por sua capacidade de armazenamento de carbono, de grande importância para a mitigação do aquecimento global. Sua preservação é de vital importância para o Brasil e para o mundo.

A Amazônia brasileira, que corresponde a $60 \%$ de sua extensão total, atingiu o ápice do desmatamento e da degradação em 2004, ano no qual a destruição da floresta atingiu $27.772 \mathrm{~km}^{2}$. A partir daí, no entanto, desenvolveu-se uma nova consciência na matéria, que impulsionou uma extraordinária queda progressiva do desflorestamento, que em 2014 ficou reduzido a $5.012 \mathrm{Km}^{2}$. o objetivo final deve ser o desmatamento líquido zero. No entanto, após 2015, os números da destruição voltaram a subir, chegando a quase $10.000 \mathrm{Km}^{2}$, em razão, sobretudo, do arrefecimento do ímpeto governamental no monitoramento, fiscalização e repressão de atividades ilícitas envolvendo a floresta. Os principais crimes ambientais praticados na Amazônia são desmatamento, queimadas, extração clandestina de madeira e mineração ilegal. A grilagem de terras públicas também constitui um grave problema.

A ocupação da Floresta Amazônica, do início dos anos 70 aos nossos dias, se deu por duas vias opostas e excludentes: de um lado, atividades econômicas como agricultura, pecuária e mineração, aliadas a grandes projetos de infraestrutura, numa visão que associava desenvolvimento a desmatamento; e, de outro lado, a preservação intocada da maior parte da floresta, mediante a criação de unidades de conservação e demarcação de terras indígenas, áreas onde eram vedadas ou altamente reguladas quaisquer atividades econômicas. Nenhum dos dois modelos foi capaz de extrair as melhores potencialidades econômicas, sociais e ambientais da floresta: o primeiro, porque fundado

\footnotetext{
${ }^{111}$ As instituições financeiras podem, ainda, incentivar a adesão a green bonds, instrumentos de financiamento para empreendimentos que geram benefícios ambientais e/ou que apoiam atividades sustentáveis. V. OECD, 2017.
} 
em uma lógica de derrubada, e o segundo porque incapaz de conter a expansão das fronteiras do desmatamento.

A bioeconomia da floresta, modelo econômico que prioriza a sustentabilidade, vem sendo concebida como um novo paradigma para o desenvolvimento econômico e social da Amazônia, por seu baixo impacto ambiental. A bioeconomia se funda em inovações no campo da tecnologia e das ciências biológicas, aliando a biodiversidade da região, os conhecimentos tradicionais e a chamada Indústria 4.0, fruto da quarta revolução industrial. Abre-se, assim, um amplo campo para novos produtos farmacêuticos, cosméticos e alimentares, bem como para a pesquisa de novos materiais e soluções energéticas. Esse novo modelo exige substanciosos investimentos em pesquisa, ciência e tecnologia, atração de recursos humanos de excelência, do Brasil e do exterior, e mecanismos eficientes de financiamento e incentivos, com parcerias públicas e privadas. Estímulo importante a essa nova perspectiva será a atitude e exigência dos mercados consumidores e financiadores quanto à sustentabilidade ambiental dos produtos que irão consumir e financiar, o que também impactaria a indústria do gado, da soja e da madeira na região, evitando novos desmatamentos e incentivando o manejo florestal adequado.

Existe uma lógica econômica e social na devastação da floresta. É uma lógica perversa, mas poderosa. Para que ela seja derrotada, é necessário um modelo alternativo consistente, capaz de trazer desenvolvimento sustentável, segurança humana e apoio da cidadania. A ignorância, a necessidade e a omissão estatal são os inimigos da Amazônia. A ciência, a inclusão social e a conscientização da sociedade serão a sua salvação.

\section{REFERÊNCIAS}

ABRAMOVAY, Ricardo. Amazônia: por uma economia de conhecimento da natureza. São Paulo: Elefante, 2019.

ABREU, Bruno R. et al. Difficulties in the control of environmental crimes in the Amazon. International Journal of Advanced Engineering Research and Science v. 6, n. 5, pp. 31-35, 2019.

AFP. Desmatamento na Amazônia aumenta 85,3\% em 2019, aponta INPE. Veja, 14 jan. 2020. Disponível em: <https://veja.abril.com.br/brasil/desmatamento-na-amazonia-aumenta-853-em2019-aponta-inpe/>.

ALMEIDA, Anna Luiza O. Colonização dirigida na Amazônia. Rio de Janeiro: IPEA, 1992.

ÁLVAREZ, Debora. Com 400 dias de governo, Bolsonaro avança sobre terras indígenas e áreas de preservação. Huffpost Brasil, 9 fev. 2020. 
AMDA - Associação Mineira de Defesa do Meio Ambiente. Garimpeiros ilegais avançam na Amazônia brasileira. AMDA (website), 3 set. 2019. Disponível em: $<$ https://www.amda.org.br/index.php/comunicacao/informacoes-ambientais/5699-garimpos-ilegaisavancam-na-amazonia-brasileira> Acesso em 24 fev. 2020.

AZEVEDO, Áurea Siqueira de Castro; VIEIRA, Thiago Almeida. Análise dos crimes ambientais registrados nas regiões do Baixo Amazonas e Tapajós, Pará, no período de 2012 a 2015. Desenvolvimento e Meio Ambiente, v. 46, 2018.

BARBOSA, Luiz C. The guardians of the Brazilian Amazon Forest. Londres: Routledge, 2015.

BARBOSA, Vanessa. Noruega suspende repasse de mais de R\$130 milhões ao Fundo Amazônia. Exame, 19 ago 2019. Disponível em: <https://exame.abril.com.br/brasil/noruega-suspende-repasse-de-maisde-r-130-milhoes-ao-fundo-amazonia/>. Acesso em 7 mar. 2020.

BARKHORDARIAN, Armineh et al. A Recent Systematic Increase in Vapor Pressure Deficit over Tropical South America. Scientific Reports, v. 9, 2019.

BARLOW, Joe et al. Clarifying Amazonia's burning crisis. Global Change Biology, 15 nov. 2019.

BARRETO, Paulo; MESQUITA, Marília. Como prevenir e punir infrações ambientais em áreas protegidas na Amazônia? Belém: Imazon, 2009.

Disponível

et al. Os frigoríficos vão ajudar a zerar o desmatamento na Amazônia? Belém: Imazon, 2017.

Lhttps:/imazon orgbr/PDFimazon/Portugues/livros/Frgoificos\%20e\%200\%20desmatamento\%20d a\%20Amaz\%C3\%B4nia.pdf>. Acesso em: 5 mar. 2020.

.; PEREIRA, Ritaumaria; ARIMA, Eugênio. A Pecuária e o desmatamento na Amazônia na Era das Mudanças Climáticas. Belém: Imazon, 2008. Disponível em: <https://imazon.org.br/publicacoes/apecuaria-e-o-desmatamento-na-amazonia-na-era-das-mudancas-climaticas/>. Acesso em: 02 abr. 2020.

BARROSO, Luís Roberto. Revolução tecnológica, crise da democracia e mudança climática: limites do direito num mundo em transformação. Revista Estudos Institucionais, v. 5, n. 3, 2019.

BECKER, Bertha K. Revisão das políticas de ocupação da Amazônia: é possível identificar modelos para projetar cenários? Parcerias Estratégicas, v. 6, n. 12, 2001.

BERGMAN, Charles. Wildlife trafficking. Smithsoniam Magazine, dez. 2009. Disponível em: <https://www.smithsonianmag.com/travel/wildlife-trafficking-149079896/>. Acesso em: 18 mar. 2020.

BNDES - Banco Nacional de Desenvolvimento Econômico e Social. Fundo Amazônia - 10 Anos:

Relatório de Atividades 2018. Brasília: BNDES, 2019. Disponível em <http://www.fundoamazonia.gov.br/export/sites/default/pt/.galleries/documentos/rafa/RAFA_2018 _port.pdf>. Acesso em 20 fev. 2020.

BOEKHOUT VON SOLIGEN, Tim. Deforestation crimes and conflicts in the Amazon. Critical Criminology, V. 18, n. 4, 2010.

BRANNSTROM, Chrisitan et al. Compliance and market exclusion in Brazilian agriculture: analysis and implications for "soft" governance. Land Use Policy, v. 29, n. 2, pp. 357-366, 2012.

BRITO, Brenda et al. Stimulus for land grabbing and deforestation in the Brazilian Amazon.

Environmental Research Letters, v. 14, 2019.

. Governo não deve premiar os ladrões de terra na Amazônia. El País Brasil, 9 set. 2019. 
BUCHERONI, Giulia. Onde está a fauna brasileira? Panorama do tráfico de animais revela futuro preocupante. G1, 24 jun. 2019.

BUTLER, Rhett A. Calculating deforestation figures for the Amazon. Mongabay, 24 abr. 2018. Disponível em: <https://rainforests.mongabay.com/amazon/deforestation_calculations.html>. Acesso em 9 fev. 2020.

CACCIAMALI, Maria Cristina; AZEVEDO, Flávio Antonio Gomes. Dilemas da erradicação do trabalho forçado no Brasil. Doutrinas Essenciais de Direitos humanos, v. 3, 2011.

CÂMARA DOS DEPUTADOS. Comissão de Integração Nacional, Desenvolvimento Regional e da

Amazônia. Câmara dos Deputados (website), s.d. Disponível em: $<$ https://www2.camara.leg.br/atividade-legislativa/comissoes/comissoes-

permanentes/cindra/amazonia-legal/mais-informacoes-sobre-a-amazonia-legal>. Acesso em 21 jan. 2019.

CAN, Özgün Emre; D'CRUZE, Neil; MACDONALD, David W. Dealing in deadly pathogens: Taking stock of the legal trade in live wildlife and potential risks to human health. Global Ecology and Conservation, v. 17, 2019. Disponível em: <https://doi.org/10.1016/j.gecco.2018.e00515>. Acesso em 2 abr. 2020.

CAPOBIANCO, João Paulo Ribeiro. Governança socioambiental na Amazônia brasileira na década de 2000. Mimeografado. Tese de doutorado submetida ao Instituto de Energia e Ambiente, Universidade de São Paulo, 2017.

CARRINGTON, Damian. Greta Thunberg tells world leaders to end fossil "madness". The Guardian, 2020.

CELENTANO, Danielle; SILLS, Erin; SALLES, Márcio; VERÍSSIMO, Adalberto. Welfare outcomes and the advance of the deforestation frontier in the Brazilian Amazon. World Developments, v. 40, n. 4, pp. 850-864, 2012.

CEPAL - Comissão Econômica para a América Latina e Caribe; IPEA - Instituto de Pesquisa Econômica Aplicada; GIZ - Deutsche Gesellschaft für Internationale Zusammenarbeit. Avaliação Independente do Plano de Ação para Prevenção e Controle do Desmatamento na Amazônia Legal: PPCDAm 20072010. Brasília: CEPAL, IPEA e GIZ, 2011. Disponível em: <http://repositorio.ipea.gov.br/bitstream/11058/884/1/IPEA_GIZ_Cepal_2011_Avaliacao\%20PPCDA m\%202007-2011_web.pdf>. Acesso em 20 fev. 2020.

CEPEA - Centro de Estudos Avançados em Economia Aplicada. PIB do agronegócio brasileiro. CEPEA (website), 6 mar. 2020. Disponível em: <https://www.cepea.esalq.usp.br/br/pib-do-agronegociobrasileiro.aspx>. Acesso em: 18 mar. 2020.

COMISSÃO PARLAMENTAR DE INQUÉRITO DA GRILAGEM. Diário da Câmara dos Deputados. Brasília: Câmara dos Deputados, 28 dez. 2001. Disponível em <https://arisp.files.wordpress.com/2009/08/relatorio-cpi-da-grilagem.pdf>. Acesso em 28 fev. 2020.

DARBY, Megan. Brazil: Bolsonaro threatens to quit Paris climate deal. Climate Exchange News, 14 ago. 2018.

DEMELLE, Brendan. Top ten climate deniers. Before the Flood (website), s.d. Disponível em: $<$ https://www.beforetheflood.com/explore/the-deniers/top-10-climate-deniers/>. Acesso em 28 jan. 2020.

DEUTSCHE WELLE. Desmatamento na Amazônia cresce 85\%. DW, 14 jan. 2020. Disponível em: <https://www.dw.com/pt-br/desmatamento-na-amazônia-cresce-85-em-2019/a-52006186>. Acesso em 28 jan. 2020. 
ESTADÃO CONTEÚDO. Ministério do Meio Ambiente reduz verba de combate à mudança climática. Exame, 7 mai. 2019.

FARIAS, Elaíze. Amazônia em chamas: 90\% da madeira exportada é illegal, diz Polícia Federal. Brasil de Fato, 16 set. 2019. Disponível em: <https://www.brasildefato.com.br/2019/09/16/amazonia-emchamas-90-da-madeira-exportada-sao-ilegais-diz-policia-federal/>. Acesso em 28 mar. 2020.

FEBRABAN - Federação Brasileira de Bancos; FGV EAESP - Centro de Estudos em Sustentabilidade. Instituições Financeiras e a Gestão do Risco de Desmatamento. São Paulo: Centro de Estudos em Sustentabilidade da Escola de Administração de Empresas de São Paulo da Fundação Getulio Vargas, 2018.

FELLET, João; COSTA, Camila. Imagens mostram o avanço do garimpo ilegal na Amazônia em 2019. BBC News, 25 jul. 2019. Disponível em: <https://www.bbc.com/portuguese/brasil-49053678>. Acesso em 3 mar. 2020.

FERNANDES, David Augusto. Soberania permanente e a proteção ambiental. Rev. Fac. Direito UFMG, n. 70, pp. 227-248, 2017.

FICHTNER, Jan; HEEMSKERK, Eelke M.; GARCIA-BERNARDO, Javier. Hidden power of the Big Three? Passive index funds, re-concentration of corporate ownership, and new financial risk. Business and Politics, v. 19, n. 2, pp. 298-326, 2017.

FOBAR, Rachel. What is the Convention on International Trade in Endangered Species? National Geographic, 3 jul. 2019.

FORTE, Bárbara; CARVALHO, Diana; RODRIGUES, Paula. O que significam as demissões de autoridades do Ministério do Meio Ambiente. ECOA/UOL, 3 mar. 2020. Disponível em: $<$ https://www.google.com.br/amp/s/www.uol.com.br/ecoa/ultimas-noticias/2020/03/03/o-quesignificam-as-demissoes-de-autoridades-do-ministerio-do-meio-ambiente.amp.htm>. Acesso em 28 mar. 2020.

FOSSIL FREE DIVESTMENT. What is fossil fuel divestment. Fossil Free (website), s/d. Disponível em: <https://gofossilfree.org/divestment/what-is-fossil-fuel-divestment/>. Acesso em 28 jan. 2020.

GALAZ, Victor et. al. Why ecologists should care about financial markets. Trends in Ecology \& Evolution, v. 30, n. 10, pp. 571-580, 2015.

GIBBS, Holly el al. Brazil's Soy Moratorium. Science v. 347, n. 6220, 2015.

. et al. Did Ranchers and Slaughterhouses Respond to Zero-Deforestation agreements in the Brazilian Amazon? Conservative Letters, v. 9, n. 1, pp. 32-42, jan./fev. 2016.

GLOBAL WITNESS. A Que Preço? Negócios irresponsáveis e o assassinato de defensores da terra e do meio ambiente em 2017. s/l: Global Witness, 2018. Disponível em: <https://www.globalwitness.org/en/campaigns/environmental-activists/a-que-pre\%C3\%A7o/>. Acesso em 20 fev. 2020.

GREENPEACE INTERNATIONAL. Eating up the Amazon. Amsterdã: Greenpeace International, 2006. Disponível em: <http://www.greenpeace.org/usa/wpcontent/uploads/legacy/Global/usa/planet3/PDFs/eating-up-the-amazon-executiv.pdf>. Acesso em 6 mar. 2020.

GREINER, Sandra et al. Moving towards next generation carbon markets: observation from article 6 ilots. s/l: Climate Focus e Perspectives, jun. 2019.

HANBURY, Shanna. Pressão para legalizar terra desmatada na Amazônia derruba chefe do INCRA. Mongabay, 3 out. 2019. Disponível em: <https://brasil.mongabay.com/2019/10/pressao-paralegalizar-terra-desmatada-na-amazonia-derruba-chefe-do-incra/>. Acesso em 28 jan. 2020. 
HARVARD BUSINESS REVIEW-BRASIL; CNI - Confederação Nacional da Indústria. Bioeconomia: uma agenda para o Brasil. Brasília: CNI, 2013.

HUMAN RIGHTS WATCH. Máfias do Ipê. Nova York: HRW, 2019. Disponível em:

<https://www.hrw.org/pt/report/2019/09/17/333886>. Acesso em 9 fev. 2020

IMAZON - Instituto do Homem e Meio Ambiente da Amazônia. Sistema de Alerta de Desmatamento. Belém: IMAZON, 2019. Disponível em: <https://imazon.org.br/wp-content/uploads/2019/12/SADOutubro-2019.pdf>. Acesso em 3 mar. 2020.

. Raio X da Ocupação da Amazônia. IMAZON (website), ago. 2013. Disponível em: <https://imazon.org.br/imprensa/a-amazonia-em-numeros/>. Acesso em 10 maio 2020.

INPA - Instituto Nacional de Pesquisas da Amazônia. PF e INPA promovem curso sobre perícia em tráfico de animais silvestres da Amazônia. INPA (website), 4 dez. 2018. Disponível em:

$<$ http://portal.inpa.gov.br/index.php/ultimas-noticias/3355-pf-e-inpa-promovem-curso-sobrepericia-em-trafico-de-animais-silvestres-da-amazonia>. Acesso em 25 fev. 2020.

INPE - Instituto Nacional de Pesquisa Espaciais. Observação da Terra. A estimativa da taxa de desmatamento por corte raso para a Amazônia Legal em 2019 é de $9.762 \mathrm{~km} 2$. INPE (website), 18 nov. 2019. Disponível em: <http://www.inpe.br/noticias/noticia.php?Cod_Noticia=5294>. Acesso em 1 mar. 2020.

.; PRODES - Instituto Nacional de Pesquisas Espaciais- Projeto de Monitoramento do Desmatamento na Amazônia Legal por Satélite. Monitoramento do desmatamento da Floresta Amazônica brasileira por satélite. Coordenação-Geral de Observação da Terra INPE (website), atualizado em nov. 2019.2 Disponível em: <http://www.obt.inpe.br/OBT/assuntos/programas/amazonia/prodes>. Acesso em 31 mar. 2020.

INTERPOL - International Criminal Police Organization; UNEP - United Nations Environment Programme. Strategic Report: Environment, Peace and Security - A Convergence of Threats. s/l: 2016. Disponível em: <www.interpol.int>. Acesso em 22 fev. 2020.

IONOVA, Ana. Illegal gold rush causing 'irreversible damage' to rivers in the Brazilian Amazon. Mongabay, 20 dez. 2019. Disponível em: <https://news.mongabay.com/2019/12/illegal-gold-rushcausing-irreversible-damage-to-rivers-in-the-brazilian-amazon/>. Acesso em 21 abril 2020.

IPAM - Instituto de Pesquisa Ambiental da Amazônia. A Grilagem de Terras Públicas na Amazônia Brasileira. Brasília: IPAM, 2006.

. Desmatamento nos assentamentos da Amazônia: histórico, tendências e oportunidades. Brasília: IPAM, 2016.

. Amazônia em Chamas: onde está o fogo - Nota técnica. Brasília: IPAM, 2019. Disponível em:

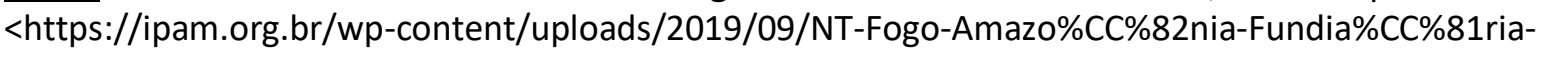
2019.pdf>.Acesso em: 02 abr. 2020.

IPCC - Intergovernmental Panel on Climate Change. Climate change 2007: Synthesis report. Geneva: IPCC, 2008.2 Disponível em: $<$ https://www.ipcc.ch/site/assets/uploads/2018/02/ar4_syr_full_report.pdf >. Acesso em 28 jan. 2020.

ISA - Instituto Socioambiental a. Campeã de requerimentos minerários, Terra Indígena Yanomami sofre com explosão do garimpo. ISA (website), 21 mar. 2019. Disponível em: $<$ https://www.socioambiental.org/pt-br/blog/blog-do-monitoramento-blog-do-rio-negro/campeade-requerimentos-minerarios-terra-indigena-yanomami-sofre-com-explosao-do-garimpo>. Acesso em 28 jan. 2020. 
.b Na Amazônia, a destruição é muito maior do que conseguimos ver. ISA (website), 22 nov. 2019. Disponível em: <https://www.socioambiental.org/pt-br/noticias-socioambientais/na-amazoniaa-destruicao-e-muito-maior-do-que-conseguimos-ver>. Acesso em 28 jan. 2020.

.c Novo arco do desmatamento: fronteira avança em 2019 na Amazônia. Brasília: ISA (website), 17 dez. 2019. Disponível em: <https://www.socioambiental.org/pt-br/noticias-socioambientais/novoarco-do-desmatamento-fronteira-de-destruicao-avanca-em-2019-na-amazonia>. Acesso em 3 mar. 2020.

.d Invasores produzem maior desmatamento em Terras Indígenas em 11 anos. Brasília: ISA (website), 13 dez. 2019. Disponível em: <https://www.socioambiental.org/pt-br/noticiassocioambientais/invasores-produzem-maior-desmatamento-em-terras-indigenas-em-11-anos $>$. Acesso em 10 maio 2020.

JIA, G., SHEVILAKOVA, E.; ARTAXO, P. et al. Land-climate interactions. In: Climate Change and Land: an IPCC special report on climate change, desertification, land degradation, sustainable land management, food security, and greenhouse gas fluxes in terrestrial ecosystems, 2019. Disponível em: < https://www.ipcc.ch/site/assets/uploads/sites/4/2019/11/05 Chapter-2.pdf>. Acesso em 11 maio 2020.

KALUNGA, Bernardo. Desmatamento na Amazônia é ideológico, diz economista Ricardo Abramovay. TAB, 2 jan. 2020.2 Disponível em: $<$ https://tab.uol.com.br/noticias/redacao/2020/01/02/desmatamento-na-amazonia-e-ideologicodiz-economista-ricardo-abramovay.htm>. Acesso em 9 fev. 2020.

LEHMACHER, Wolfgang. Wildlife crime: a $\$ 23$ billion trade that's destroying our planet. World Economic Forum, 28 set. 2016.

LIBÓRIO, Bárbara. Por que o IBAMA arrecada só $5 \%$ das multas ambientais que aplica. Aos Fatos, 31 jan. 2019. Disponível em: <https://aosfatos.org/noticias/por-que-o-ibama-arrecada-so-5-das-multasambientais-que-aplica/>. Acesso em 28 mar. 2020.

LYNCH, Michael J.; STRETESKY, Paul B. Green Criminology. In: CULLEN, Francis T.; WILCOX, Pamela. The Oxford Handbook on Criminological Theory. Oxford: Oxford University Press, 2012.

LOVEJOY, Thomas E.; NOBRE. Carlos. Amazon Tipping Point. Science Advances, 2018. Disponível em: <http://advances.sciencemag.org/content/4/2/eaat2340>. Acesso em 10 maio 2020.

MAHAR, Dennis. Desenvolvimento econômico da Amazônia: uma análise das políticas governamentais. Rio de Janeiro: IPEA/INPES, 1978.

MICHAELOWA, Axel; JOTZO, Frank. Transaction costs, institutional rigidities and the size of the clean development mechanism. Energy Policy, v. 33, 2001. Disponível em:

<https://doi.org/10.1016/j.enpol.2003.08.016>. Acesso em 28 mar. 2020.

MINISTÉRIO DA DEFESA. Operação Verde Brasil combateu 1,7 mil focos de incêndio. 3 out. 2019. Ministério da Defesa, Disponível em: <https://www.defesa.gov.br/noticias/61430-operacao-verdebrasil-combate-quase-2-mil-focos-de-incendios>.

MMA - Ministério do Meio Ambiente. Plano de Ação para Prevenção e Controle do Desmatamento na Amazônia Legal (PPCDAm) - 3a fase (2012-2015): Pelo uso sustentável e conservação da floresta. Brasília: 2013.2 Disponível em: <https://www.mma.gov.br/images/arquivo/80120/PPCDAm/_FINAL_PPCDAM.PDF>. Acesso em 21 mar. 2020.

.a ENREDD+ Estratégia nacional para redução das emissões provenientes do desmatamento e da degradação florestal, conservação dos estoques de carbono florestal, manejo sustentável de 
florestas e aumento de estoques de carbono florestal. Brasília: MMA, 2016. Disponível em: $<\mathrm{http}: / /$ redd.mma.gov.br/images/publicacoes/enredd_documento_web.pdf $>$. Acesso em: $06 \mathrm{mar}$. 2020 .

.b Plano de Ação para Prevenção e Controle do Desmatamento na Região Amazônica. REDD+ Brasil (website), 2016. Disponível em: <http://redd.mma.gov.br/pt/acompanhamento-e-a-analise-deimpacto-das-politicas-publicas/ppcdam>. Acesso em 19 fev. 2020

.a Plano de Ação para Prevenção e Controle do Desmatamento na Amazônia Legal. Ministério do Meio Ambiente. Ministério do Meio Ambiente (website), s/d. Disponível em:

$<$ https://www.mma.gov.br/informma/item/616-prevenção-e-controle-do-desmatamento-naamazônia>. Acesso em 20 mar. 2020.

.b Biomas. MMA (website), s/d. Disponível em: <https://www.mma.gov.br/biomas.html>. Acesso em 16 mar. 2020.

MORLEY, Robert. Origin and evolution of tropical rainforest. Chichester: Wiley, 2000.

MPF - Ministério Público Federal, Mineração ilegal de ouro na Amazônia: marcos jurídicos e questões controversas. Brasília: MPF, 2020, p. 8.

NASA - National Aeronautics and Space Administration.a Scientific consensus: Earth's climate is warming. Global Climate Change, s.d.a. Disponível em: <https://climate.nasa.gov/scientificconsensus/>. Acesso em 28 jan. 2020.

.b What is the greenhouse effect? Global Climate Change (website), s.d. Disponível em: <https://climate.nasa.gov/faq/19/what-is-the-greenhouse-effect/>. Acesso em 8 mar. 2020.

NEGRÃO, Heloísa. Após Alemanha, Noruega também bloqueia repasses para Amazônia. El País, 16 ago. $2019 . \quad$ Disponível em: <https://brasil.elpais.com/brasil/2019/08/15/politica/1565898219_277747.html>. Acesso em 7 mar. 2020.

NEPSTAD, Daniel; STICKLER, Claudia; ALMEIDA, Oriana. Globalization of the Amazon Soy and Beef Industries: Opportunities for Conservation. Conservation Biology, v. 20, n. 6, 2006.

. et. al., Slowing Amazon deforestation through public policy and interventions in beef and soy supply chains. Science, v. 344, n. 6188, pp. 1118-1123, 2014.

NOBRE, Antônio Donato. O futuro climático da Amazônia: Relatório de avaliação científica. São Paulo: ARA, CCST-INPE, INPA, 2014.

NOBRE, Carlos et al. Land-use and climate change risks in the Amazon and the need of a novel sustainable development paradigm. PNAS, v. 113, n. 39, pp. 10759-10768, 2016.

NOBRE, Ismael; NOBRE, Carlos. Projeto "Amazônia 4.0": definindo uma terceira via para a Amazônia. Futuribles em Português, n. 27, 2019.

NOGUEIRA, Renata Campos; SOARES, Milena. Patenting bioactive molecules from biodiversity: the Brazilian experience. Expert Opinion on Therapeutic Patents, v. 20, n. 2, p. 145-157, 2010.

NWF - National Wildlife Federation; GLUE - Gibbs Land Use and Environmental Lab. A Path Towards Zero Deforestation Cattle. Zero Deforestation Cattle (website), s/d. Disponível em:<http://www.zerodeforestationcattle.org/\#/home>. Acesso em 5 mar. 2020.

OECD - Organisation for Economic Co-operation and Development. The bioeconomy to 2030: designing a policy agenda. Paris: OECD Publishing, 2009. Disponível em:

$<$ http://www.oecd.org/futures/long- 
termtechnologicalsocietalchallenges/thebioeconomyto2030designingapolicyagenda.htm>. Acesso em 23 mar. 2020.

. Mobilizing Bond Markets for a Low-Carbon Transition, Green Finance and Investment. Paris: OECD Publishing, 2017.

OIT - Organização Internacional do Trabalho, Combatendo o trabalho escravo contemporâneo: o exemplo do Brasil. Brasília: OIT, 2010, p. 48-53.

. Perfil dos principais atores envolvidos no trabalho escravo rural no Brasil. Brasília: OIT, 2011.

OLIVEIRA, Marcelo. Bolsonaro: país tem 'indústria de demarcação' e reservas indígenas abusivas. UOL, 11 fev. 2020.

OPEN SOURCE SYSTEMS. 31,000 scientists say "no convincing evidence". Open Source Systems (website), s.d. Disponível em: <http://ossfoundation.us/projects/environment/globalwarming/myths/31000-scientists-say-no-convincing-evidence>. Acesso em 28 jan. 2020.

PIB - Povos Indígenas no Brasil. Localização e extensão das Tis. PIB (website), página atualizada em 21 fev. 2019. Disponível em: <https://pib.socioambiental.org/pt/Localização_e_extensão_das_TIs>. Acesso em 20 mar. 2020.

POTTER, Gary R. What is green criminology? Green Criminology (website), s.d. Disponível em:

<https://greencriminology.org/about-green-criminology/>. Acesso em 22 fev. 2020.

PRESIDÊNCIA DA REPÚBLICA. Plano de Ação para Prevenção e Controle do Desmatamento na Amazônia Legal - PPCDAm 1a Fase. Brasília: Casa Civil/PR, 2004. Disponível em:

<https://www.mma.gov.br/images/arquivo/80120/PPCDAM_fase1.pdf>. Acesso em: 02 mar. 2020.

RECIO, María Eugenia. Dancing like a toddler? The Green Climate Fund and REDD+ International rulemaking. Review of European, Comparative \& International Environmental Law, v. 28, 2019.

RENCTAS. Ambientebrasil - Tráfico de animais silvestres. RENCTAS (website), 27 set. 2019. Disponível em: <http://www.renctas.org.br/ambientebrasil-trafico-de-animais-silvestres/>. Acesso em 25 fev. 2020.

REUTERS. Focos de incêndio na Amazônia sobem 30\% em comparação com 2018, diz INPE. Reuters, 8 jan. 2020. Disponível em: <https://br.reuters.com/article/idBRKBN1Z800N-OBRTP>. Acesso em 23 fev. 2020.

ROCHA, Lilian Rose Lemos. Desmatamento e Queimadas na Amazônia. Curitiba: Juruá, 2017.

RODRIGUES, Ana S. L. et al. Boom-and Bust Development Patterns Across the Amazon Deforestation Frontier. Science, v. 324, p. 1435-1437, 2009.

ROMM, Joseph. Is there a difference between global warming and climate change? The Years Project (website), s.d. Disponível em <https://theyearsproject.com/ask-joe/difference-global-warmingclimate-change/>. Acesso em 28 jan. 2020.

ROOSEVELT, A.C. et al. Paleoindian cave dwellers in the Amazon: the peopling of the Americas. Science, v. 272 n. 5260, pp. 373-384, 1996.

ROSA, Ana Beatriz. Em primeiro ano, governo Bolsonaro expõe despreparo para lidar com questões ambientais. Huffpost, 2 jan. 2020.

SALLES, João Moreira; ESTEVES, Bernardo. O mundo sem a Amazônia. Revista Piauí, 17 out. 2019.

SCHOLTENS, Bert. Why Finance Should Care About Ecology. Trends in Ecology and Evolution, v. 32, n.
pp.
500-505,
2017.
Disponível
em:

7 , 
<https://www.sciencedirect.com/science/article/abs/pii/S0169534717300915>. Acesso em 6 mar. 2020.

SCHWAB, Klaus. The fourth industrial revolution. N. York: Crown Business, 2017.

SCIENCE AND TECHNOLOGY CONCEPTS MIDDLE SCHOOL. What is photosynthesis? Smithsoniam Science Education Center (website), 12 abr. 2017. Disponível em: <https://ssec.si.edu/stemvisionsblog/what-photosynthesis>. Acesso em 31 jan. 2020.

SCIENTISTS OF THE AMAZON COUNTRIES AND GLOBAL PARTNERS. Scientific Framework to save the Amazon. s/l: Conservation International, 30 set. 2019. Disponível em: $<$ https://www.conservation.org/docs/default-

source/brasil/ascientificframeworktosavetheamazonfinalversion.pdf>. Acesso em 23 mar. 2020.

SMITH, Sprit. Human activities are drying out the Amazon: NASA study. NASA Global Climate Change (website), 5 nov. 2019.

SONTER, Laura et al. Mining drives extensive deforestation in the Brazilian Amazon. Nature Communications, v. 8, 2017. Disponível em : <https://www.nature.com/articles/s41467-017-00557w\#citeas>. Acesso em 9 fev. 2020.

STABILE, Marcelo C.C. et al. Solving Brazil's land use puzzle: Increasing production and slowing Amazon deforestation. Land Use Policy, v. 91, 2020. Disponível em: <http://doi.org/10.1016/j.landusepol.2019.104362>. Acesso em 29 fev. 2020.

STACHEWSKI, Ana Laura. Bolsonaro mantém Ministério do Meio Ambiente, mas esvazia pasta. Época Negócios, 22 jan. 2019.2 Disponível em: <https://epocanegocios.globo.com/Brasil/noticia/2019/01/bolsonaro-mantem-ministerio-do-meioambiente-mas-esvazia-pasta.html>.

SUBBARAO, Srikanth; LLOYD, Bob. Can the Clean Development Mechanism (CDM) deliver? Energy Police, v. 39, n. 3, pp. 1600-1611, 2011. Disponível em: <https://doi.org/10.1016/j.enpol.2010.12.036>. Acesso em 28 jan. 2020.

SUDAM - Superintendência de Desenvolvimento da Amazônia. Boletim Amazônia. Belém: SUDAM, n. 2, 2016.2 Disponível em: <http://www.sudam.gov.br/conteudo/menus/centraldeconteudo/boletimamazonia/2\%20BOLETIM\%20AMAZ\%C3\%94NIA\%20-\%20Volume\%202\%20(Revisado_V2).pdf>. Acesso em: 02 abr. 2020.

SULLIVAN, Zoe. Mining activity causing nearly 10 percent of Amazon deforestation. Mongabay, 2 nov. 2017.

TCU- Tribunal de Contas da União. Versão Simplificada das Contas do Governo da República - Exercício de 2009. Brasília: 2010.2 TCU, Disponível em: <https://portal.tcu.gov.br/tcu/paginas/contas_governo/contas_2009/Textos/Ficha\%204\%20\%20Arrecadacao\%20de\%20Multas.pdf>. Acesso em 22 fev. 2020. TRAVIS, D.A.; WATSON, R.P.; TAUE, A. The spread of pathogens through trade in wildlife. Rev. sci. tech. Off. int. Epiz., v. 30, n. 1, 2011. Disponível em: <https://www.ncbi.nlm.nih.gov/pubmed/21809766>. Acesso em: 02 abr. 2020.

UN - United Nations, World Commission on Environment and Development. Report of the World Commission on Environment and Development: Our Common Future. Oxford: Oxford University Press, 1987.

In larger freedom: towards development, security and human rights for all (Report of the Secretary-General). Nova York: United Nations. General Assembly, 2005. 
. Draft da decisão de adoção do Acordo de Paris. Paris: UN, 2015. Disponível em:

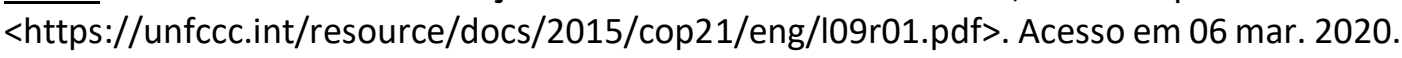

UNDP - United Nations Development Program. Human Development Report. Oxford: Oxford University Press, 1994.

UNEP - United Nations Environment Programme. Environmental crimes are on the rise, so are efforts to prevent them. UNEP (website), 21 set. 2018. Disponivel em: $<$ https://www.unenvironment.org/news-and-stories/story/environmental-crimes-are-rise-so-areefforts-prevent-them>. Acesso em 22 fev. 2020.

UNESCO - United Nations Educational, Scientific and Cultural Organization. Sustainable development. UNESCO (website), s/d. Disponível em: <https://en.unesco.org/themes/education-sustainabledevelopment/what-is-esd/sd>. Accesso em 24 jan. 2020.

UNODC - United Nations Office on Drugs and Crime. Wildlife crime worth USD 8-10 billion annually, ranking it alongside human trafficking, arms and drug dealing in terms of profit: UNODC chief. UNODC (website), 13 mai. 2014.2 Disponível em: https://www.unodc.org/unodc/en/frontpage/2014/May/wildlife-crime-worth-8-10-billionannually.html >. Acesso em 09 mai. 2020.

NARAIN, Urvashi; VAN'T VELD, Klaas. The clean development mechanism's low-hanging fruit problem: When might it arise, and how might it be solved?, Environmental and Resource Economics, v. 40, n. 3, pp. 445-465, 2008. Disponível em: <https://doi.org/10.1007/s10640-007-9164-x>. Acesso em 09 mai. 2020.

VAL, Adalberto Luis. Caminhos para manter a floresta de pé. In: BNDES. Amazônia em debate: oportunidades, desafios e soluções. Rio de Janeiro: BNDES, 2010. Disponível em: <https://web.bndes.gov.br/bib/jspui/bitstream/1408/1906/2/Amaz\%C3\%B4nia\%20em\%20debate_o portunidades\%2C\%20desafios\%20e\%20solu\%C3\%A7\%C3\%B5es\%20final-A_P.pdf>. Acesso em 19 mar. 2020.

VARELLA, Marcelo Dias. O surgimento e a evolução do direito internacional do meio ambiente: da proteção da natureza ao desenvolvimento sustentável. In: BARROS-PLATIAU, Ana Flávia; VARELLA, Marcelo Dias (org.). Proteção internacional do meio ambiente. Brasília: Unitar, UniCEUB e UnB, 2009. Disponível em: <https://repositorio.uniceub.br/jspui/handle/235/11334>. Acesso em 12 mar. 2020.

VASCONCELLOS, Patrícia Mara Cabral. Vozes da exclusão: os assassinatos de defensores de direitos humanos na Amazônia. Revista Interdisciplinar de Direitos Humanos, v. 7, n. 2, 2019.

VENTURA, Dalila. La banda de científicos que descobrió las reglas que rigen la vida en el planeta y puso de cabeza nuestra visión del mundo. BBC News Mundo, 12 jan. 2020. Disponível em:

<http://www.cgp168.com/?mundo/noticias-51012368>. Acesso em 31 jan. 2020.

VERÍSSIMO, Beto. Let's cut Amazon deforestation to zero. Here's how. Americas Quarterly, 9 nov. 2015.

. Bases para um blue print desenvolvimento sustentável na Amazônia. Mimeografado, 2020.

VIAL, Luiz Antônio Machado; SETTE, Tânia Cristina Campanhol; SELITO, Miguel Afonso. Cadeias produtivas - Foco na cadeia produtiva dos produtos agrícolas. Trabalho apresentado no III Encontro de Sustentabilidade em Projeto do Vale do Itajaí, 15, 16 e 17 de abr 2009. Disponível em: <https://ensus2009.paginas.ufsc.br/files/2015/09/CADEIAS-PRODUTIVAS-UNISINOS.pdf>. Acesso em 21 mar. 2020. 
VIANA, Virgílio. Financing REDD: How Government Funds Can Work with the Carbon Market. IIED (International Institute for Enviroment and Development) Briefing, jun. 2009.

VICK, Mariana. Quais as causas e os tipos de queimadas na Amazônia. Nexo, 19 nov. 2019. Disponível em: $\quad$ https://www.nexojornal.com.br/expresso/2019/11/19/Quais-as-causas-e-os-tipos-dequeimadas-na-Amazônia>. Acesso em 23 fev. 2020.

VILELA, Pedro Rafael. Bolsonaro defendeu não realizar COP-25 no Brasil. Agência Brasil, 28 nov. 2018. Disponível em: <https://agenciabrasil.ebc.com.br/politica/noticia/2018-11/bolsonaro-defendeu-naorealizar-cop-25-no-brasil>. Acesso em: 02 abr. 2020.

WALLACE, Scott. Inside the faltering fight against illegal Amazon logging. National Geographic, 28 aug. 2019. Disponível em: <https://www.nationalgeographic.com/environment/2019/08/brazil-logging/>. Acesso em 23 jan. 2020.

WENZEL, Fernanda. Amazonas, Acre e Rondônia querem o seu próprio Matopiba. Amazônia: notícia e informação, 9 mar. 2020. Disponível em: <http://amazonia.org.br/2020/03/amazonas-acre-erondonia-querem-o-seu-proprio-matopiba/>. Acesso em 19 mar. 2020.

WORLAND, Justin. How Davos became a climate change conference. Time, 27 jan. 2020.

WORLD BANK, Why the Amazon's biodiversity is critical for the globe: an interview with Thomas Lovejoy. World Bank, 2019 Disponível em: <https://www.worldbank.org/en/news/feature/2019/05/22/why-the-amazons-biodiversity-iscritical-for-the-globe>. Acesso em 23 mar. 2020.

Trabalho enviado em 14 de maio de 2020

Aceito em 14 de maio de 2020 